Application of Ensemble Sensitivity Analysis to Observation Targeting for Short-term Wind Speed Forecasting

J. Zack, E. Natenberg, S. Young, J. Manobianco, C. Kamath

February 23, 2010 
This document was prepared as an account of work sponsored by an agency of the United States government. Neither the United States government nor Lawrence Livermore National Security, LLC, nor any of their employees makes any warranty, expressed or implied, or assumes any legal liability or responsibility for the accuracy, completeness, or usefulness of any information, apparatus, product, or process disclosed, or represents that its use would not infringe privately owned rights. Reference herein to any specific commercial product, process, or service by trade name, trademark, manufacturer, or otherwise does not necessarily constitute or imply its endorsement, recommendation, or favoring by the United States government or Lawrence Livermore National Security, LLC. The views and opinions of authors expressed herein do not necessarily state or reflect those of the United States government or Lawrence Livermore National Security, LLC, and shall not be used for advertising or product endorsement purposes.

This work performed under the auspices of the U.S. Department of Energy by Lawrence Livermore National Laboratory under Contract DE-AC52-07NA27344. 


\section{Application of Ensemble Sensitivity Analysis to Observation Targeting for Short-term Wind Speed Forecasting}

John Zack, Eddie Natenberg, Steve Young, John Manobianco

AWS Truewind, LLC

Chandrika Kamath

Lawrence Livermore National Laboratory

22 February 2010 


\section{Introduction}

The operators of electrical grids, sometimes referred to as Balancing Authorities (BA), typically make critical decisions on how to most reliably and economically balance electrical load and generation in time frames ranging from a few minutes to six hours ahead. At higher levels of wind power generation, there is an increasing need to improve the accuracy of 0 - to 6-hour ahead wind power forecasts. Forecasts on this time scale have typically been strongly dependent on short-term trends indicated by the time series of power production and meteorological data from a wind farm. Additional input information is often available from the output of Numerical Weather Prediction (NWP) models and occasionally from off-site meteorological towers in the region surrounding the wind generation facility.

A widely proposed approach to improve short-term forecasts is the deployment of off-site meteorological towers at locations upstream from the wind generation facility in order to sense approaching wind perturbations. While conceptually appealing, it turns out that, in practice, it is often very difficult to derive significant benefit in forecast performance from this approach. The difficulty is rooted in the fact that the type, scale, and amplitude of the processes controlling wind variability at a site change from day to day if not from hour to hour. Thus, a location that provides some useful forecast information for one time may not be a useful predictor a few hours later. Indeed, some processes that cause significant changes in wind power production operate predominantly in the vertical direction and thus cannot be monitored by employing a network of sensors at off-site locations. Hence, it is very challenging to determine the type of sensors and deployment locations to get the most benefit for a specific short-term forecast application.

Two tools recently developed in the meteorological research community have the potential to help determine the locations and parameters to measure in order to get the maximum positive impact on forecast performance for a particular site and short-term look-ahead period. Both tools rely on the use of NWP models to assess the sensitivity of a forecast for a particular location to measurements made at a prior time (i.e. the look-ahead period) at points surrounding the target location. The fundamental hypothesis is that points and variables with high sensitivity are good candidates for measurements since information at those points are likely to have the most impact on the forecast for the desired parameter, location and look-ahead period.

One approach is called the adjoint method (Errico and Vukicevic, 1992; Errico, 1997) and the other newer approach is known as Ensemble Sensitivity Analysis (ESA; Ancell and Hakim 2007; Torn and Hakim 2008). Both approaches have been tested on large-scale atmospheric prediction problems (e.g. forecasting pressure or precipitation over a relatively large region 24 hours ahead) but neither has been applied to mesoscale space-time scales of winds or any other variables near the surface of the earth.

A number of factors suggest that ESA is better suited for short-term wind forecasting applications. One of the most significant advantages of this approach is that it is not necessary to linearize the mathematical representation of the processes in the underlying atmospheric model as required by the adjoint approach. Such a linearization may be especially problematic for the application of short-term forecasting of boundary layer winds in complex terrain since non-linear shifts in the structure of boundary layer due to atmospheric stability changes are a critical part of the wind power production forecast problem.

The specific objective of work described in this paper is to test the ESA as a tool to identify measurement locations and variables that have the greatest positive impact on the accuracy of 
wind forecasts in the 0- to 6-hour look-ahead periods for the wind generation area of California's Tehachapi Pass during the warm (high generation) season. The paper is organized as follows. Section 2 highlights the methodology, Section 3 presents results, and Section 4 concludes with a summary and brief discussion of future work.

\section{Methods}

The ESA approach uses data generated by a set (ensemble) of perturbed NWP simulations for a sample time period to statistically diagnose the sensitivity of a specified forecast variable for a target location (the forecast metric) to parameters at other locations and prior times [the initial condition (IC) state variable]. The ensemble of NWP simulations are produced by starting with a single initial state at the beginning of the analysis period and introducing statistical perturbations into the initial and lateral boundary conditions. This process generates a set of simulations that differ from each other due to the perturbations. The number of simulations must be large enough to produce a statistically significant sample for the sensitivity calculations. Typically, 48 or more ensemble members have been used in previous large-scale ESA applications (Torn and Hakim, 2008). However, there have been no published studies documenting the sensitivity of results to the number of the ensemble members.

Each of these initial states is then used as the starting point for an NWP simulation. The NWP simulations are marched forward in time with periodic assimilation of observational data for a representative period of time referred to as the "analysis period". The periodic assimilation of measurement data serves to keep the model state from drifting too far from the actual atmospheric conditions. However, it is important to keep the spread of the ensemble within an acceptable range in order to obtain meaningful results.

Ensemble spread can be controlled by specifying characteristics of the initial condition perturbations through user-definable parameters. The initial perturbations are typically chosen to be relatively large (i.e. larger than the observation uncertainty in the initial state) so that each ensemble member is unique. The ensemble spread then typically decreases during the "spin up" of the ensemble and eventually comes into a balance within some general range that is indicative of the characteristics of the flow regime. For the Tehachapi Pass experiment, the range or standard deviation of horizontal wind speed was on the order of 3 to $5 \mathrm{~m} / \mathrm{s}$.

Excessive ensemble divergence is usually not a problem since an increase in spread causes the members to adjust more to fit the available observed values. So initially large ensemble spread will eventually decrease by assimilating observations. On the other hand, convergence of ensemble members is more of an issue. A technique called covariance inflation (Anderson and Anderson 1999; Anderson 2007) is used to avoid ensemble convergence (i.e. large decrease in spread for highly predictable flows). Covariance inflation perturbs the members in areas of low spread based on user-specified values for the inflation parameters.

The ensemble of simulations produces a large volume of three-dimensional data from each ensemble member at periodic intervals throughout the analysis period. A statistical analysis is then performed on these data to determine the sensitivity $(\partial \mathrm{F} / \partial \mathrm{s})$ of a target forecast metric $(\mathrm{F})$ to selected IC state variables (s) from prior simulated times at all points in the model domain. This sensitivity relationship can be expressed as

$$
\frac{\partial F}{\partial s}=\frac{\operatorname{cov}(F, s)}{\operatorname{var}(s)},
$$


where the covariance (cov) and variance (var) are computed over all ensemble members (Ancell and Hakim 2007).

In the Tehachapi Pass application, the forecast metric (F) was the average $80-\mathrm{m}$ wind speed over a rectangular area encompassing most of the wind generation resources in the Pass. A set of ten IC state variables (s) were evaluated. The simulations were generated on a three-dimensional grid matrix of 200 by 200 horizontal points with a horizontal spacing of $4 \mathrm{~km}$ and 38 vertical layers that covered most of southern California (area depicted in Figure 1). They were produced using version 2.2 of the Weather Research and Forecast (WRF) atmospheric model (Skamarock et al. 2005) and observational data were assimilated every 6 hours using an ensemble Kalman filter data assimilation procedure within the Data Assimilation Research Testbed (DART) software (Anderson 2001; Anderson et al. 2009). A total of 48 ensemble members were used in the analysis. Appendix A lists details of the WRF model configuration, ensemble Kalman filter data assimilation system, and types of data assimilated

The simulation period extended from 7 July to 25 August 2008. This period was selected to represent warm season conditions in Tehachapi Pass. The first two days were designated as a "spin-up" period and the data were not used in the sensitivity calculations. Therefore, the analysis period covered 45 days from 0000 UTC 9 July to 0000 UTC 25 August 2008.

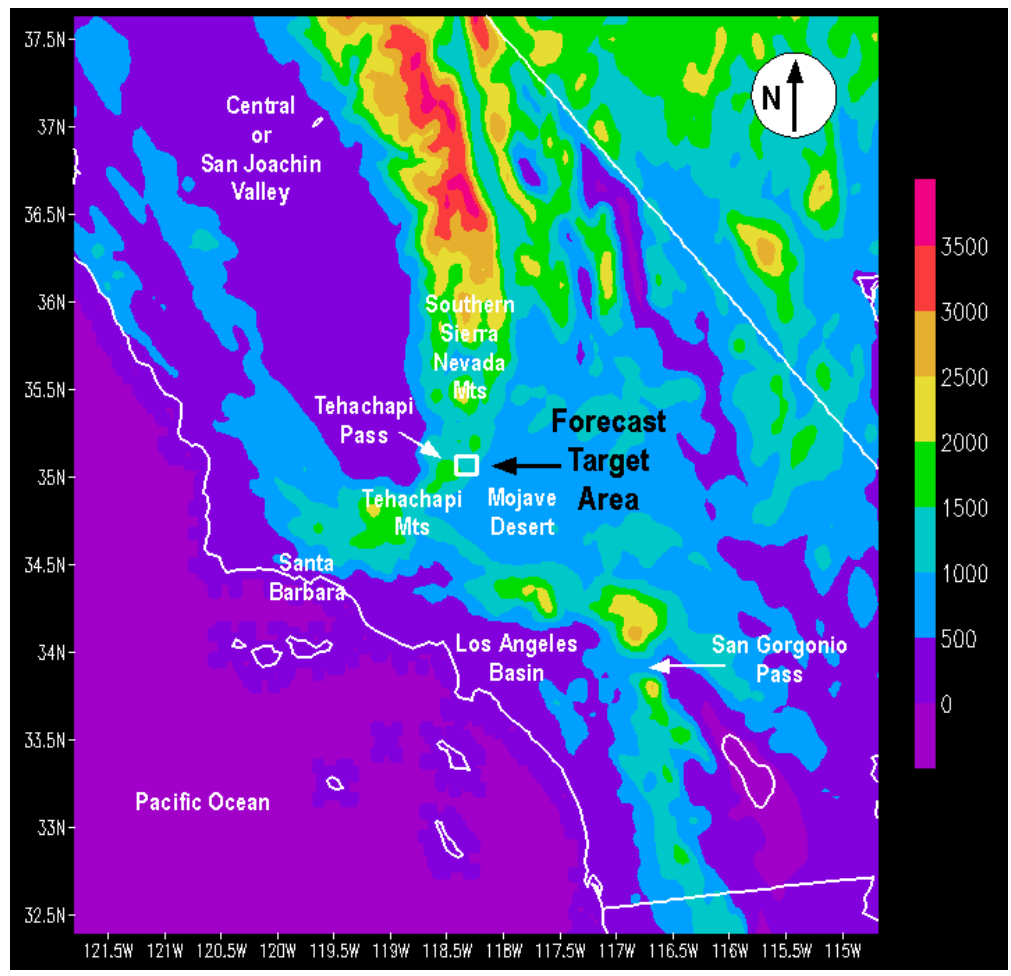

Figure 1. The geographical area covered by the NWP model's grid domain used in the Tehachapi Pass ensemble sensitivity analysis experiments. A matrix of 200 by 200 horizontal points with a spacing of approximately $4 \mathrm{~km}$ between points was overlaid on this domain. The color shading depicts the terrain elevation $(\mathrm{m})$ on the scale of the model grid. The white box denotes the forecast target area, i.e. the area over which the average forecast metric ( $80-\mathrm{m}$ wind speed) is calculated. 


\section{Results}

The results presented in this section address only the 3-hour forecast look-ahead period that is of greatest interest to the grid operator in California. However, a similar analysis was done for the 1-, 2-, 4-, 5-, and 6-hour look-ahead periods with data from the same ensemble of simulations. The relative magnitude of the sensitivity among the IC variables was similar for all look-ahead periods with the same IC variables having the highest and lowest sensitivity magnitudes. However, the patterns were somewhat different with the most significant high sensitivity areas closer to the forecast target area for the shorter look-ahead periods (e.g. 1 and 2 hours) and further away for the longer ones (e.g. 5 and 6 hours). These results suggest that the same variables have the greatest value to the forecast for all look-ahead periods but that the optimal location for the measurement changes with the look-ahead period.

\subsection{Case Example}

The output data from the ensemble of simulations provide a large volume of information about the space-time connection of atmospheric variability within the simulation domain and can be analyzed in many different ways. The approach used in this investigation follows that employed by Torn and Hakim (2008) in their analysis of forecast sensitivity of day-ahead forecasts over the western portion of the state of Washington. In their approach, the sensitivity of the forecast metric variable to a particular IC state variable for a specific forecast time and look-ahead period is determined by constructing a linear relationship between the forecast metric values $(\mathrm{F})$ and the values of a prior IC state variable (s) at a particular model grid point based on data from all of the ensemble members. Figure 2 illustrates an example of the data from all of the ensemble members and the resulting linear relationship for $\mathrm{F}$ defined as the average $80-\mathrm{m}$ wind speed in a rectangular area in Tehachapi Pass for 0300 UTC 10 Aug 2008. In this case, the IC state variable is the $80-\mathrm{m}$ wind speed three hours earlier at grid point $(82,114)$, which is located in the central valley to the northwest of Tehachapi Pass (point A in Figure 4). Each data point denotes the value of the $80-\mathrm{m}$ wind speed at grid point $(82,114)$ from 0000 UTC and the average 80 -m wind speed in the Tehachapi Pass target area at 0300 UTC from one of the 48 ensemble members.

The plot indicates that there is well-defined relationship between the changes in the $80-\mathrm{m}$ wind speed at point $(82,114)$ at 0000 UTC and changes in the average $80-\mathrm{m}$ wind speed over the forecast target area three hours later. The slope of the regression line through these points defines the sensitivity of the forecast metric to this specific IC variable and location for the date, time, and look-ahead period under consideration. The interpretation of the regression line is that a 1 $\mathrm{m} / \mathrm{s}$ change in the $80-\mathrm{m}$ wind speed at point $(82,114)$ is associated with a $1.94 \mathrm{~m} / \mathrm{s}$ change in the $80-\mathrm{m}$ wind speed in the Tehachapi Pass target area three hours later. The $\mathrm{R}^{2}$ value for this regression is a relatively high 0.415 , which indicates that the variation on the $80-\mathrm{m}$ wind speed at 0000 UTC explains approximately $41 \%$ of the variance in the forecast target metric 3 hours later.

Another set of data from all of the ensemble members for the same date and time is shown in Figure 3. The forecast metric is the same (80-m wind speed in the Tehachapi Pass target area) but the IC state variable is the 80 -m wind speed at a different model grid point $(19,28)$, which is denoted as point B in Figure 4. This point is located over the Pacific Ocean to the southwest of the Los Angeles Basin. For this point, there is essentially no relationship between changes in the $80-\mathrm{m}$ wind speed among the ensemble members at 0000 UTC and the 80-m wind speed three hours later in the Tehachapi Pass target area. This result is indicated by the fact that slope of the 
regression line associated with this data is essentially zero and the $\mathrm{R}^{2}$ value is also approximately zero, which indicates this variable explains none of the variance of the forecast metric three hours later.

A spatial representation of the sensitivity patterns for a particular date and time can be created by constructing a contour map of the sensitivity values (i.e. the slopes of the regression lines between each grid point and the target area). The map for 0300 UTC 10 Aug 2008 is shown in Figure 4. The forecast target region is represented by the white box. The map indicates that there is a region of high sensitivity in the central valley to the north and northwest of Tehachapi Pass for this time period.

The sensitivity calculation is not restricted to the same variable that is used to define the forecast metric. Sensitivity values can be calculated with respect to any variable that can be derived from the basic set of prognostic variables in the NWP model used to generate the ensemble of simulations.

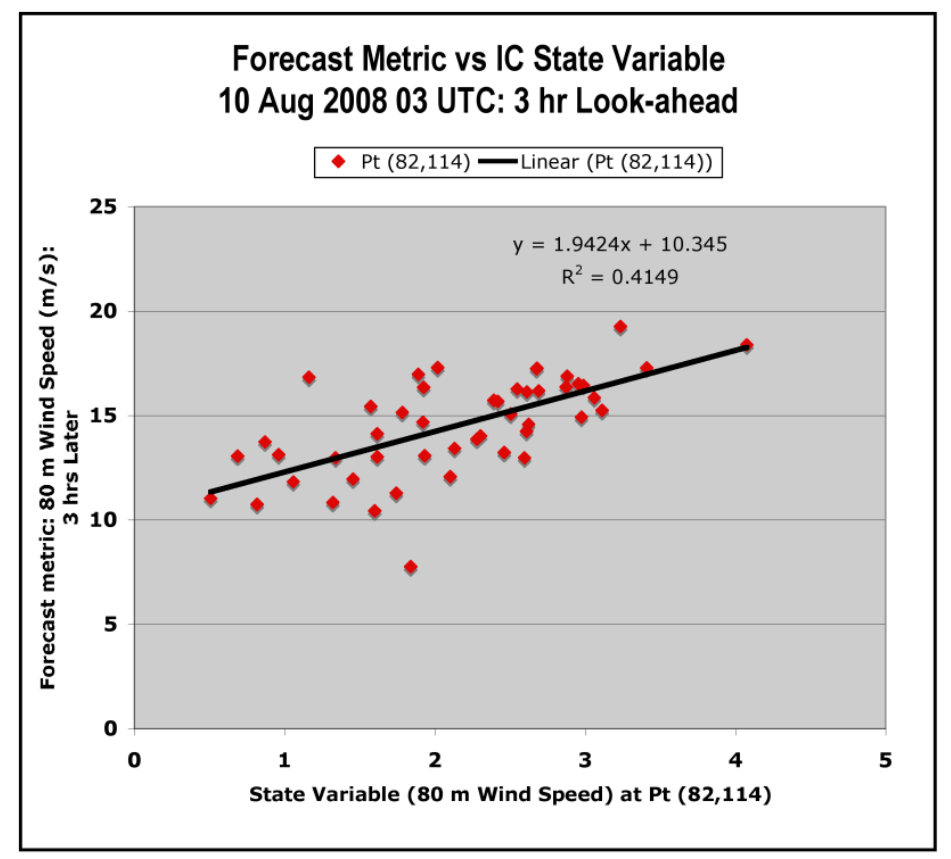

Figure 2. Scatter plot of initial condition state variable (80-m wind speed) for model grid point $(82,114)$ at 0000 UTC 10 August versus forecast metric $(80-\mathrm{m}$ wind speed) at 0300 UTC from each of the 48 ensemble members and the associated regression line. 


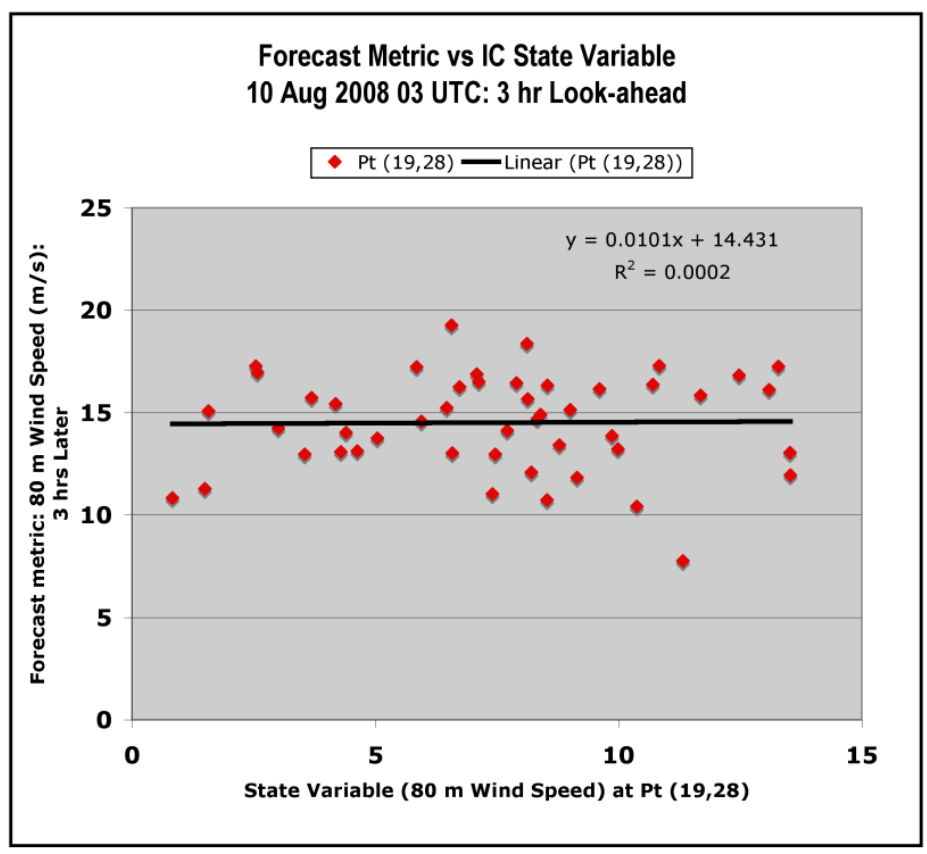

Figure 3. Scatter plot of initial condition state variable ( $80-\mathrm{m}$ wind speed) for model grid point $(19,28)$ at 0000 UTC 10 August versus forecast metric $(80-\mathrm{m}$ wind speed) at 0300 UTC from each of the 48 ensemble members and the associated regression line.

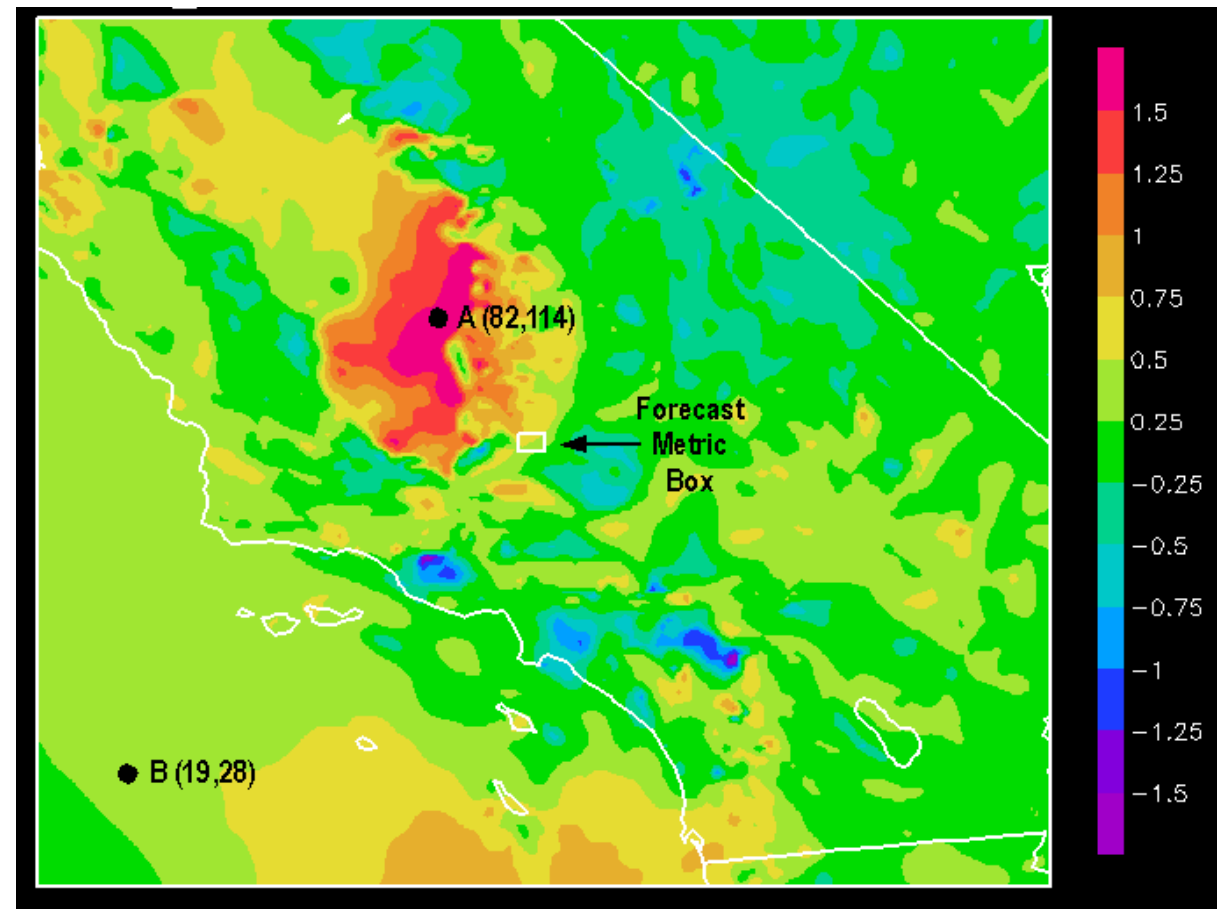

Figure 4. Forecast sensitivity of the average $80-\mathrm{m}$ wind speed in the white box (forecast metric box) at 0300 UTC 10 August 2008 (2000 PDT 9 August) to 80-m wind speed three hours earlier. The locations for which the ensemble data are depicted in Figures 2 (point A) and 3 (point B) are also shown. The color shading indicates the change in the 80-m wind speed within the metric box associated with a change in the 80-m wind speed at a point in the domain three hours earlier. 


\subsection{Diurnal Variability}

It is known that the warm season wind regime in Tehachapi Pass is characterized by a prominent diurnal pattern whose amplitude and phase is modulated by the larger scale atmospheric weather features. This pattern is shown in Figure 5, which depicts the average wind speed $(\mathrm{m} / \mathrm{s})$ by hour of the day over the southeastern portion of Tehachapi Pass (i.e. approximately the area of the forecast metric box) for the warm season. The average wind speed graph suggests that there may be a diurnal cycle in the pattern and amplitude of the forecast sensitivity. If the diurnal cycle is significant, then it may be valuable to analyze the forecast sensitivity by time of day. These results could then be used to develop a sensor deployment strategy that weights more heavily the sensitivity patterns at times of day most critical for a specific forecast application.

The diurnal variability of the forecast sensitivity was investigated by computing the average sensitivity of the 3-hour forecast of 80-m wind speed to 80-m wind speed over a sub-domain area surrounding the metric box for each day in the analysis period. The geographical region enclosed by sub-domain area is depicted in Figure 6. The size of the sub-domain was selected to represent approximately the area in which propagating features could influence the Tehachapi target region within a 3-hour period given a typical propagation speed for low-level atmospheric features.

The standard deviation of the sub-domain average sensitivity (SAS) was calculated for each day to provide an index of the amount of variability in sensitivity experienced on each day of the analysis period. The average daily standard deviation of the SAS was $0.15 \mathrm{~m} / \mathrm{s}$ or $13.9 \%$ of the average SAS for the analysis period. However, the standard deviation exhibited considerable day-to-day variability ranging from a high of about $0.27 \mathrm{~m} / \mathrm{s}$ on 25 July to a low of $0.02 \mathrm{~m} / \mathrm{s}$ on 16 August (Figure 7).

The average diurnal pattern of the 3-hr forecast SAS to the $80-\mathrm{m}$ wind speed is shown in Figure 8. The results indicate that the sensitivity was highest during the morning hours (0800-1100 PDT) after sunrise when the flow through the pass is weak and shallow. The lowest SAS was during the late afternoon and early evening (1700-2000 PDT) when the flow through the pass is deepest and strongest. 


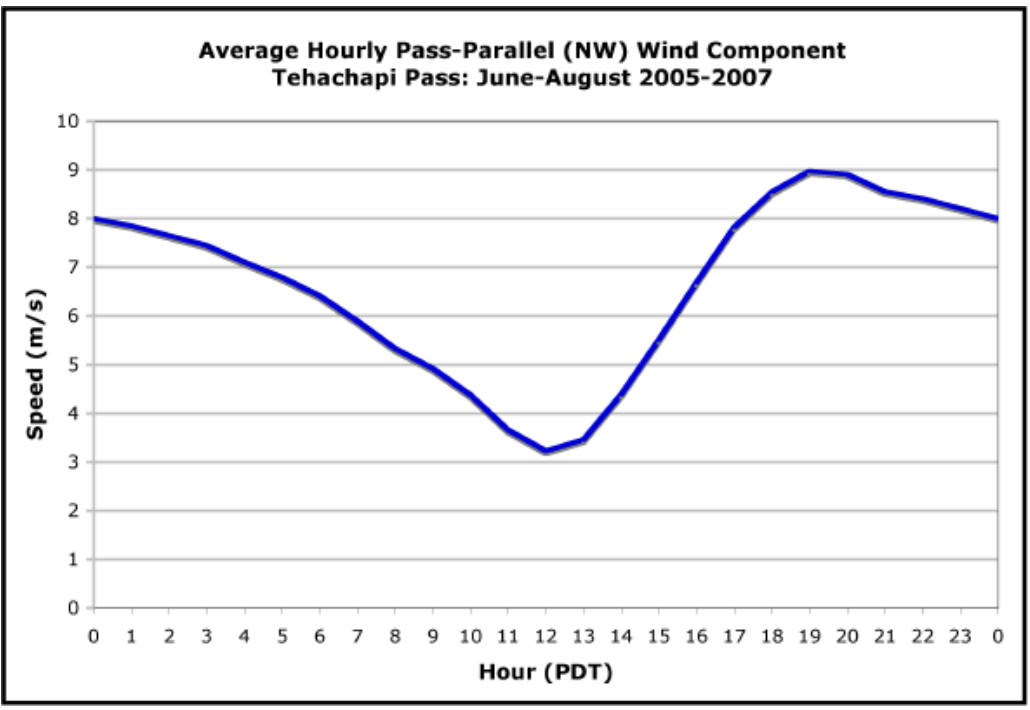

Figure 5. Average warm-season wind speed by hour of the day for a set of anemometers on the southeastern side of Tehachapi Pass, which is roughly coincident with the forecast metric box.

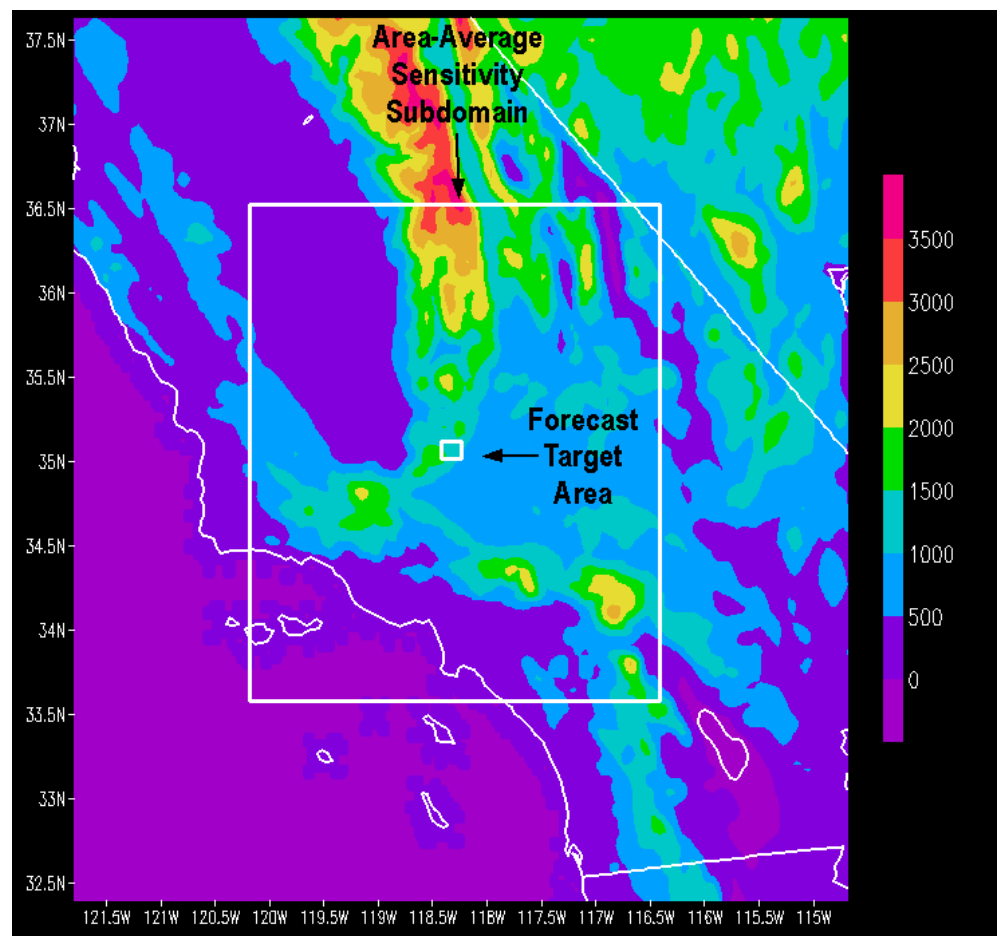

Figure 6. A map depicting the sub-domain (large white box) used to compute an areaaverage sensitivity for a region surrounding the Tehachapi Pass forecast target area. 


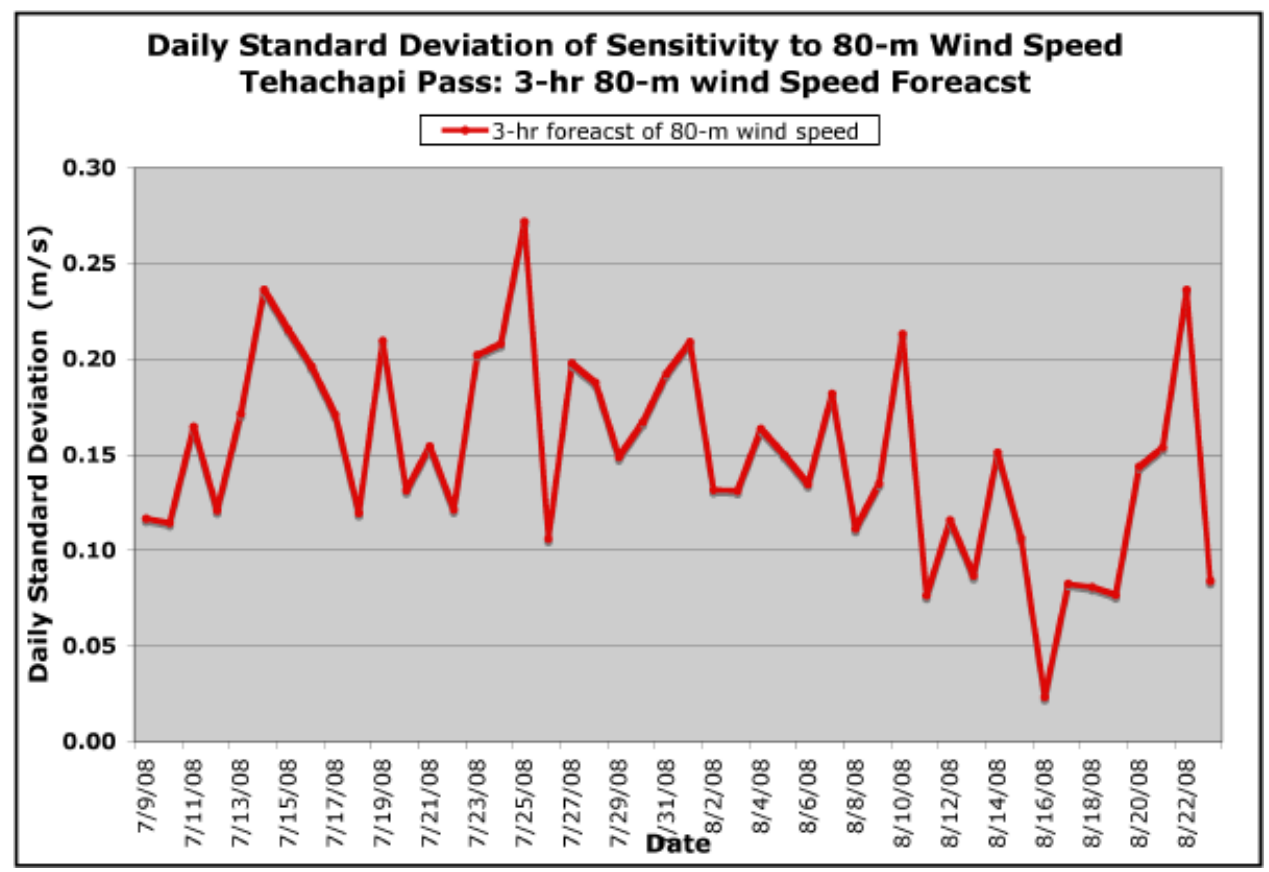

Figure 7. Standard deviation of the sub-domain average sensitivity for each day in the analysis. The area of the sub-domain is shown in Figure 6.

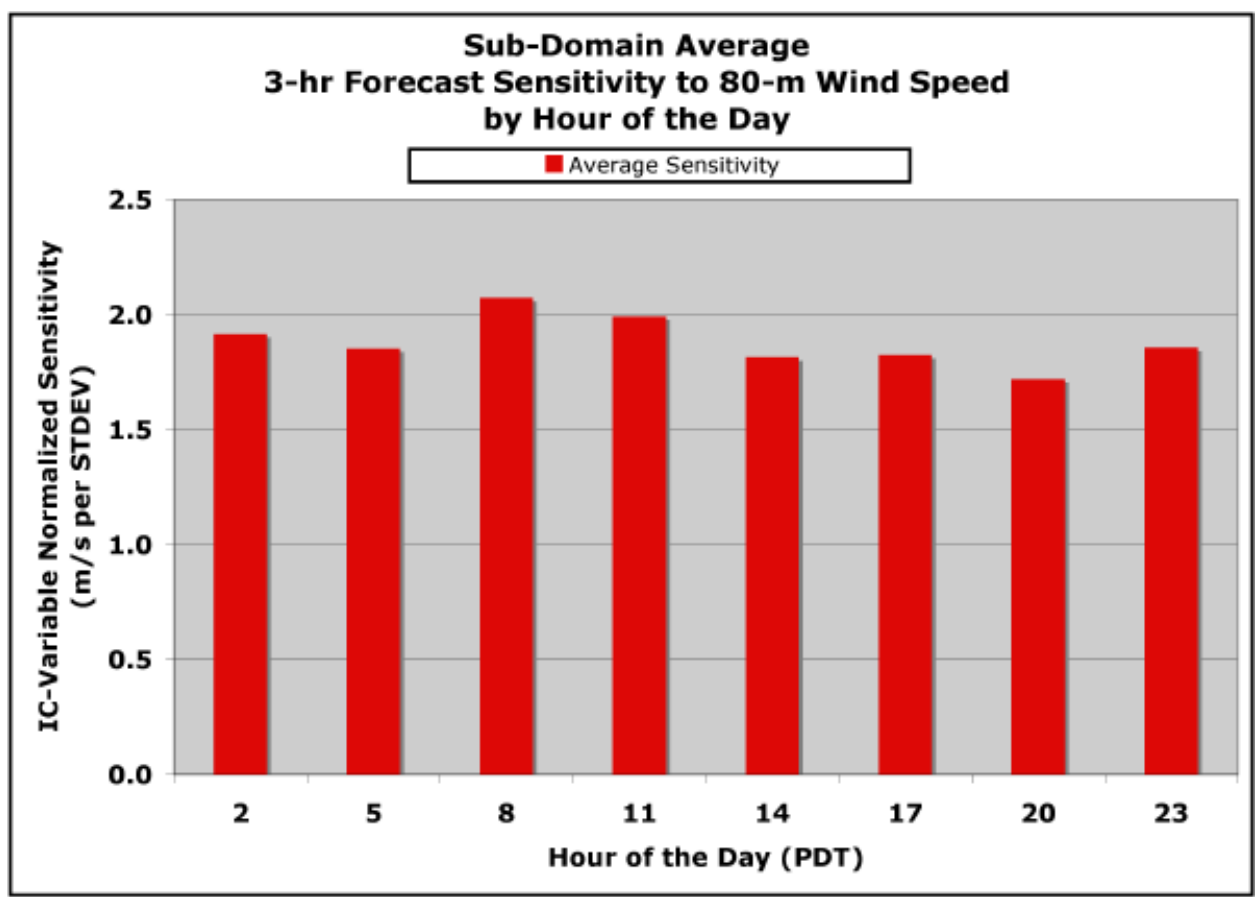

Figure 8. Sub-domain average sensitivity of a 3-hr forecast of the $80-\mathrm{m}$ wind speed in the Tehachapi Pass metric box to the normalized initial condition variable of $80-\mathrm{m}$ wind speed. 


\subsection{Day to Day Variability}

The sensitivity of forecasts also varies considerably from day to day. Periods of high sensitivity are generally characterized by larger forecast errors since the forecast metric is more sensitive to variations in the prior state of the atmosphere (i.e. the initial conditions). The day-to-day variability was analyzed by using the SAS values computed over the sub-domain shown in Figure 6.

A daily average SAS value for a 3-hour forecast was computed for each day in the analysis period for three different initial condition variables: (1) 80-m wind speed, (2) northwest component of the wind at $1.5-\mathrm{km}$ above mean sea level (AMSL), and (3) the $25-\mathrm{m}$ to $1-\mathrm{km}$ temperature difference (Figure 9). There is a strong tendency for days with high or low sensitivity to one of these variables to also be days of the correspondingly high or low sensitivity to the other variables. These results demonstrate that the day-to-day variability of sensitivity to each of these variables is highly correlated and the forecasts on some days are more sensitive than on other days.

For example, the highest daily average SAS for all three IC variables occurred on 13 July while the SAS values for 16 August are among the lowest for all three IC variables. The spatial patterns of the sensitivity for 0600 UTC on 13 July (highest average sensitivity) and 16 August (lowest average sensitivity) are shown in Figures 10 and 11, respectively. These plots indicate that the sensitivity to the $80-\mathrm{m}$ wind speed three hours earlier was high over a large area on 16 July while it was generally near zero on 16 August except for some isolated points.

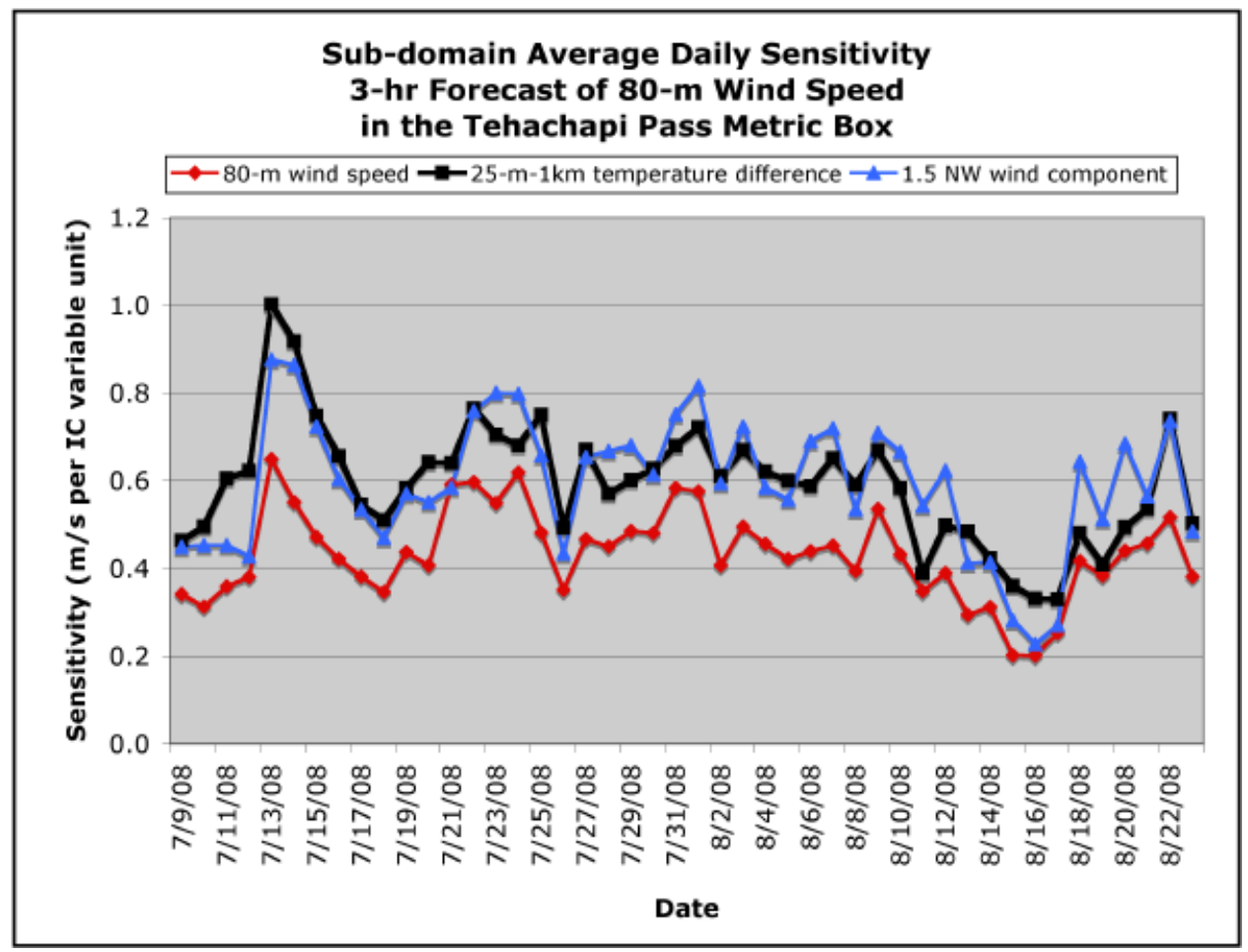

Figure 9. Average daily sensitivity of a 3-hr forecast of the average $80-\mathrm{m}$ wind speed in the Tehachapi Pass forecast metric box for each day in the analysis period to three different IC variables over the sub-domain depicted in Figure 6. 


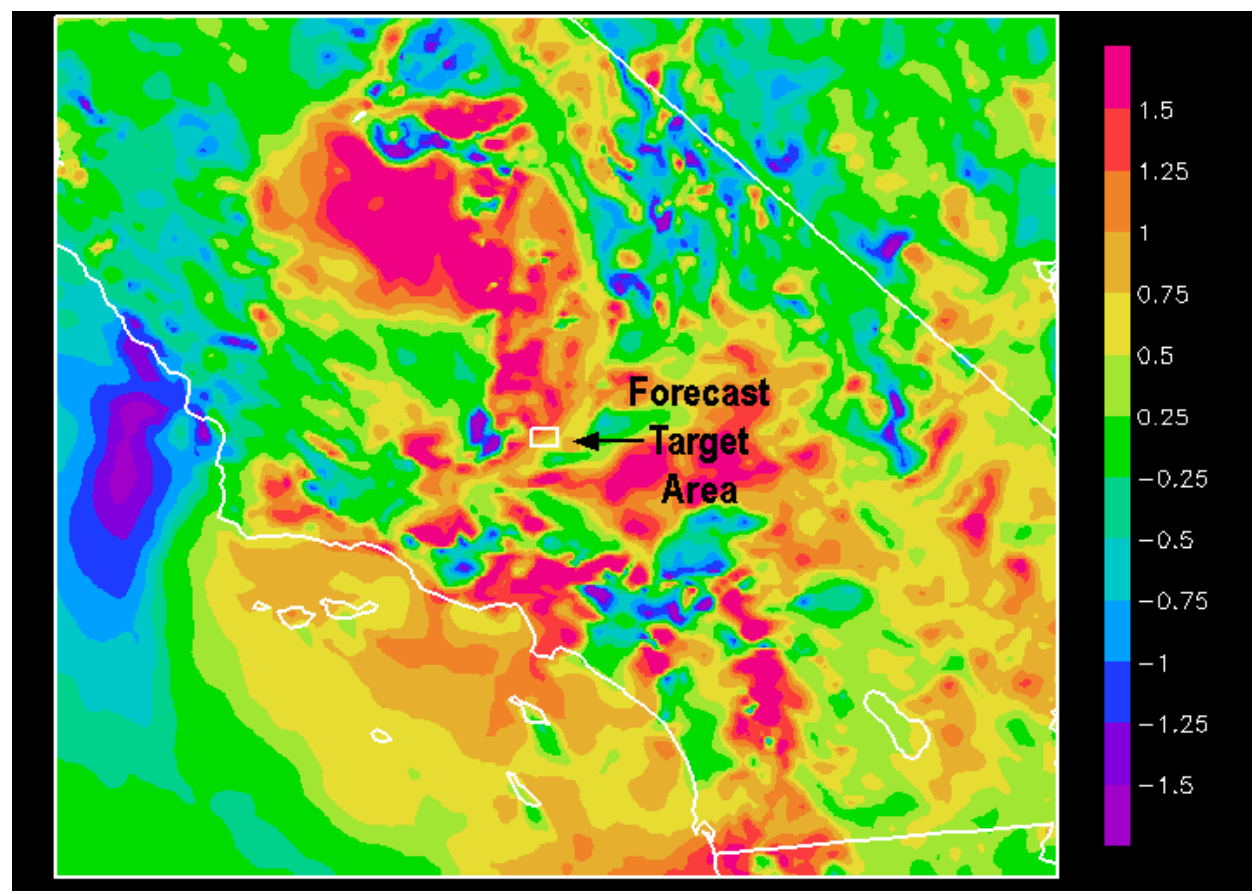

Figure 10. Sensitivity of a 3-hour forecast of the average $80-\mathrm{m}$ wind speed in the white box at 0600 UTC 13 July 2008 (2300 PDT 12 July) to the $80-\mathrm{m}$ wind speed at all points in the simulation domain

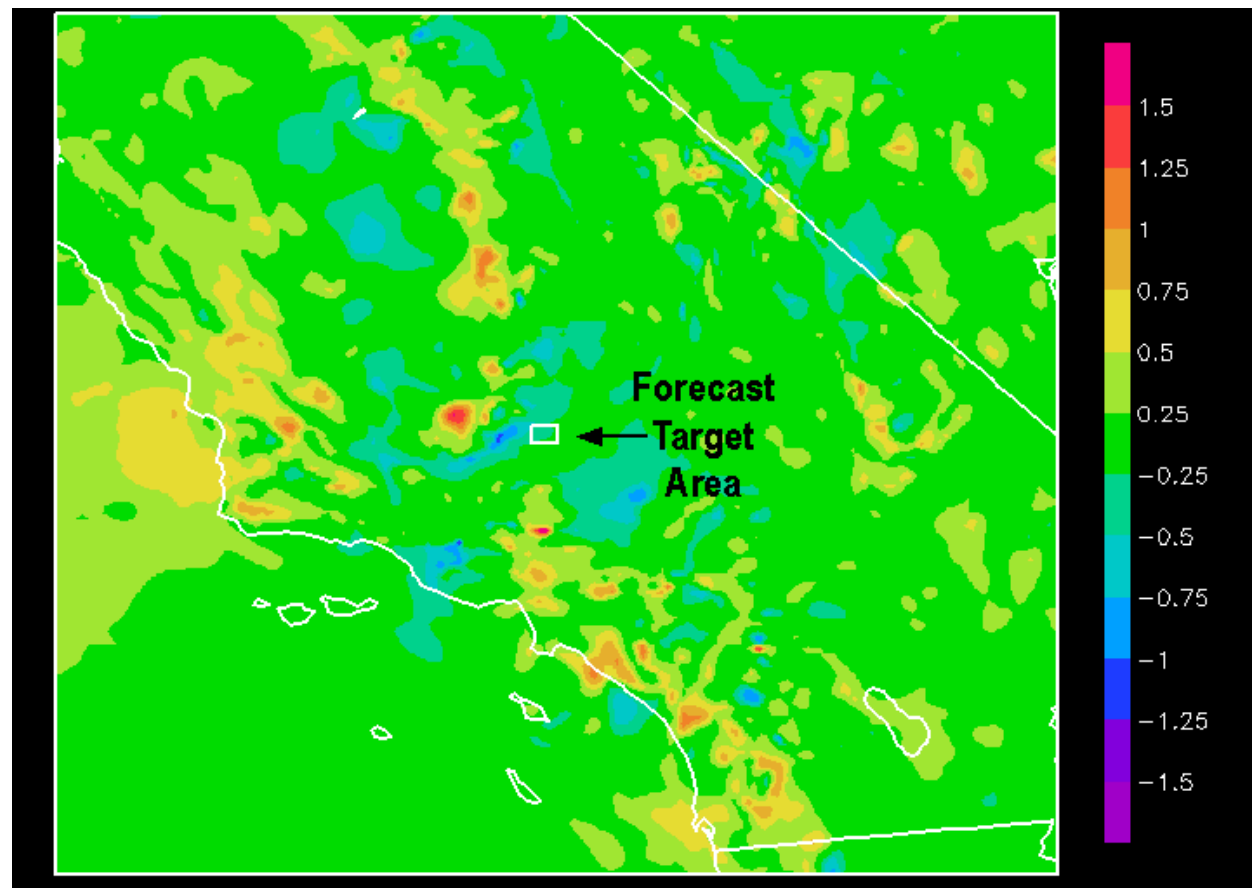

Figure 11. Sensitivity of a 3 -hour forecast of the average $80-\mathrm{m}$ wind speed in the white box at 0600 UTC 16 August 2008 (2300 PDT 15 August) to the 80-m wind speed at all points in the simulation domain 


\subsection{Climatology}

The data presented in the previous section indicate that there is often a considerable amount of variability in the sensitivity patterns within a day and from day to day. In order to make inferences about the best measurement locations and variables to improve forecast performance over a time period composed of a wide variety of cases, it is necessary to construct some type of statistical composite of the sensitivity values over a representative sample of cases. The simplest composite is an average although that statistic may not be the most meaningful or useful parameter for every application. The average can be constructed for all dates and times in the analysis period to obtain information about which areas have the highest average sensitivity over all cases. The average can also be constructed by time of day to obtain a representation of any diurnal cycles in the sensitivity patterns.

In addition, the average could be computed for specific subsets of the analysis period - such as those which experience large changes (ramps) in wind power production or time periods during which a particular wind or weather regime was present (such as northwest or southeast flow). This approach would yield information about the locations and variables that have the most sensitivity for those types of events. The regime-based approach may be particularly valuable if the objective is to create a network of measurements, which address a range of weather regimes and not just the most common regime. Event-based analysis may not have as much value for the reduction of the forecast error over a large sample of cases but it may be more valuable for reducing the error in certain critical situations associated with particular weather regimes.

Another composite statistic that can be employed is the frequency of statistically significant nonzero sensitivity. In this approach, the statistical significance of the sensitivity being non-zero at a specified confidence level is determined for each forecast interval at each grid point. The frequency of non-zero sensitivity can then be compiled for each point and used to create a map of the frequencies. Points with high values indicate locations to where the forecast is frequently sensitive. However, it does not provide information about which points typically have high sensitivity. This issue can be addressed by altering the frequency of statistically significant sensitivity calculation to employ a sensitivity magnitude threshold greater than zero. This approach could provide information about which points have a high frequency of relatively high sensitivity.

The analysis performed in this project considered both the average sensitivity as well as the frequency of statistically significant non-zero sensitivity at the $95 \%$ confidence level for the entire analysis period and also for a subset of cases when observed ramps were identified. The climatology for the entire period is presented in Section 3.4.1 and the climatology for the ramp event subsample is summarized in Section 3.4.2.

\subsubsection{All Cases}

The average sensitivities over all time periods in the 45-day analysis period for four selected IC variables are shown in Figures 12 through 15. These four IC variables produced the largest normalized sensitivity values and had the most coherent spatial patterns of the 10 IC variables that were considered in this study. Figure 12 illustrates the average 3-hour forecast sensitivity of the 80-m wind speed in the target region (white box) to 80-m wind speeds three hours earlier. This map indicates that there are areas of high average sensitivity to the north and northwest of Tehachapi Pass. The average sensitivity over much of the domain is near zero indicating that $80-$ 
$\mathrm{m}$ wind speed measurements in most locations would have little value for 3-hour forecasts of 80$\mathrm{m}$ wind speed in the target region.

Previous analyses (Lin and Jao 1995; Watson et al 2009) of flow through Tehachapi Pass indicate that it is sensitive to the hydrostatic stability of the air entering the Pass and of the air layer above the Pass. This result provides motivation to examine the forecast sensitivity to the low-level atmospheric stability. The temperature difference between $25 \mathrm{~m}$ and $1 \mathrm{~km}$ above ground level was used as a metric of the low-level atmospheric stability. The patterns indicate that there is a well-defined region of high positive average sensitivity to this IC state variable in an area to the northwest of Tehachapi Pass (Figure 13). An increase in the 25-m to 1-km temperature difference in this area is associated with an increase in the 80-m wind speed in the target region three hours later. An increase in this temperature difference indicates that the air in the lowest kilometer of the atmosphere has become less stable. However, there is also a small area of negative sensitivity (dark blue) to the north-northeast of the target area. The negative values indicate an inverse sensitivity, which means that a decrease in the $25-\mathrm{m}$ to $1-\mathrm{km}$ temperature difference in this area is associated with an increase in the $80-\mathrm{km}$ wind speed in the target area three hours later.

It is interesting to note that the area of positive sensitivity is in a region where the surface elevation is well below the elevation of Tehachapi Pass whereas the area of negative sensitivity is in a region where the terrain elevation is similar or higher than the elevation of the Pass. Higher wind speeds in the metric area are favored when the layer below Pass level over the Central Valley is more unstable and the upper layer over the Pass is more stable. This result is very consistent with the physics of the dominant mode of warm season flow through the Pass.

Figures 14 and 15 depict the average 45-day sensitivity of a 3-hour 80-m wind speed forecast to winds at two higher levels in the atmosphere: $1.5 \mathrm{~km}(\sim$ the $850 \mathrm{hPa}$ pressure level $)$ and $3 \mathrm{~km}(\sim$ the $700 \mathrm{hPa}$ pressure level) AMSL. In both cases, the actual IC variable under consideration was the northwest-southeast component of the flow at the specified level and not the total wind speed. This parameter was selected because previous studies of the flow through the Pass have indicated that the flow in the Pass is more sensitive to strength of the Pass-parallel component of the upper level wind speed than to the actual wind speed.

The sensitivity to the Pass-parallel component of the $1.5-\mathrm{km}$ wind is shown in Figure 14. In general, the sensitivity pattern is much smoother than it is for the $80-\mathrm{m}$ wind speed or the vertical temperature difference IC variables. This result is most likely due to complexity of the earth's surface (terrain, roughness etc.) and the diurnal cycle of the winds at this level. The highest sensitivity values are concentrated in an area just to the northwest of the Pass. The typical flow in the warm season at this level is from the northwest so stronger upstream Pass-parallel flow generally leads to higher 80-m wind speeds in the Pass three hours later.

The sensitivity pattern to the Pass-parallel component of the 3-km wind is much more diffuse than the $1.5-\mathrm{km}$ pattern. The maximum sensitivity values are positive which indicates that a stronger Pass-parallel component even at the 3-km level is associated with a stronger 80-m wind speed. However, the maximum sensitivity is in a broad area to the south and southeast of the Pass. 


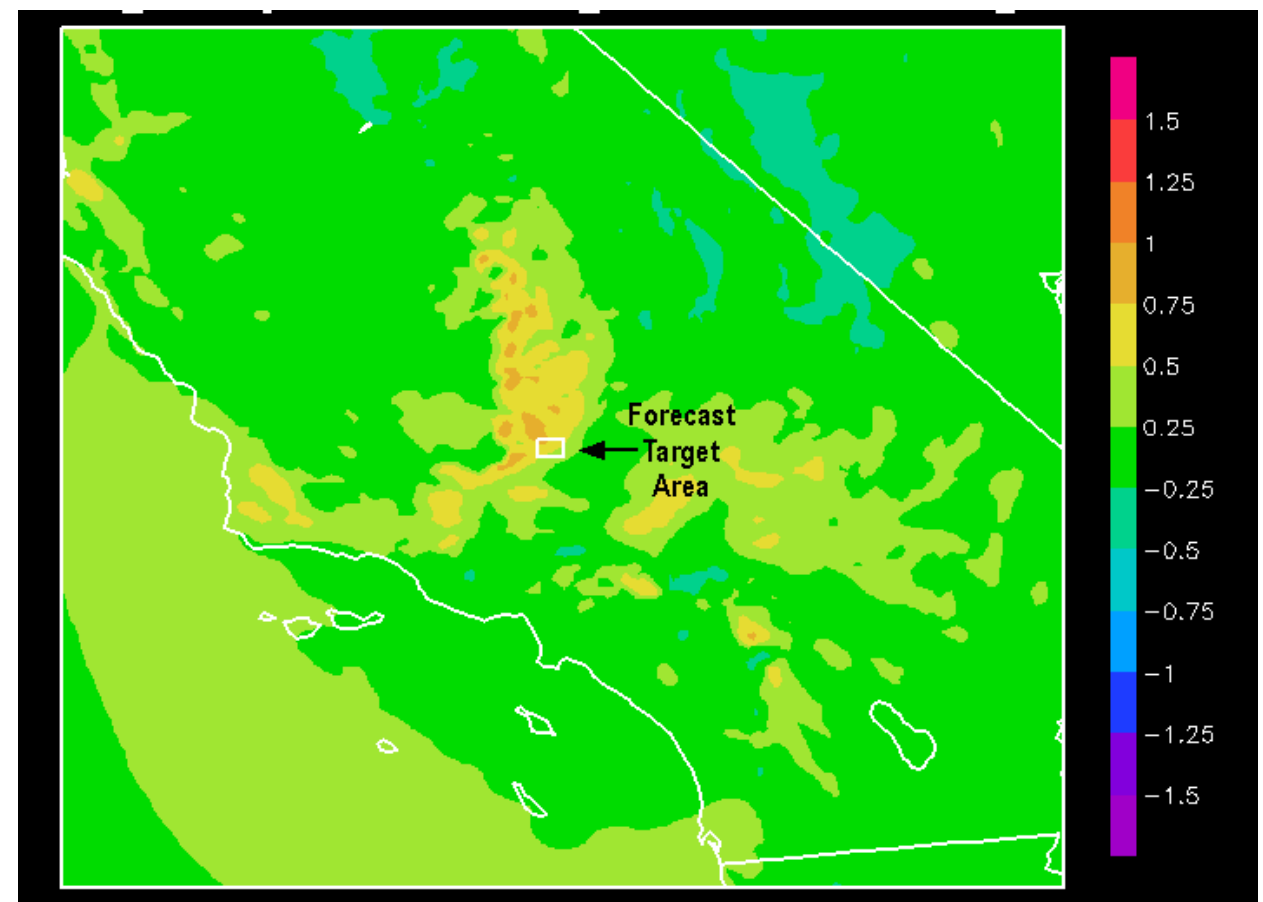

Figure 12. Average sensitivity of $80-\mathrm{m}$ wind speed $(\mathrm{m} / \mathrm{s})$ within the white target box to $80-\mathrm{m}$ wind speed $(\mathrm{m} / \mathrm{s})$ throughout the entire grid domain for a 3-hour forecast for all time periods in the 45-day analysis period.

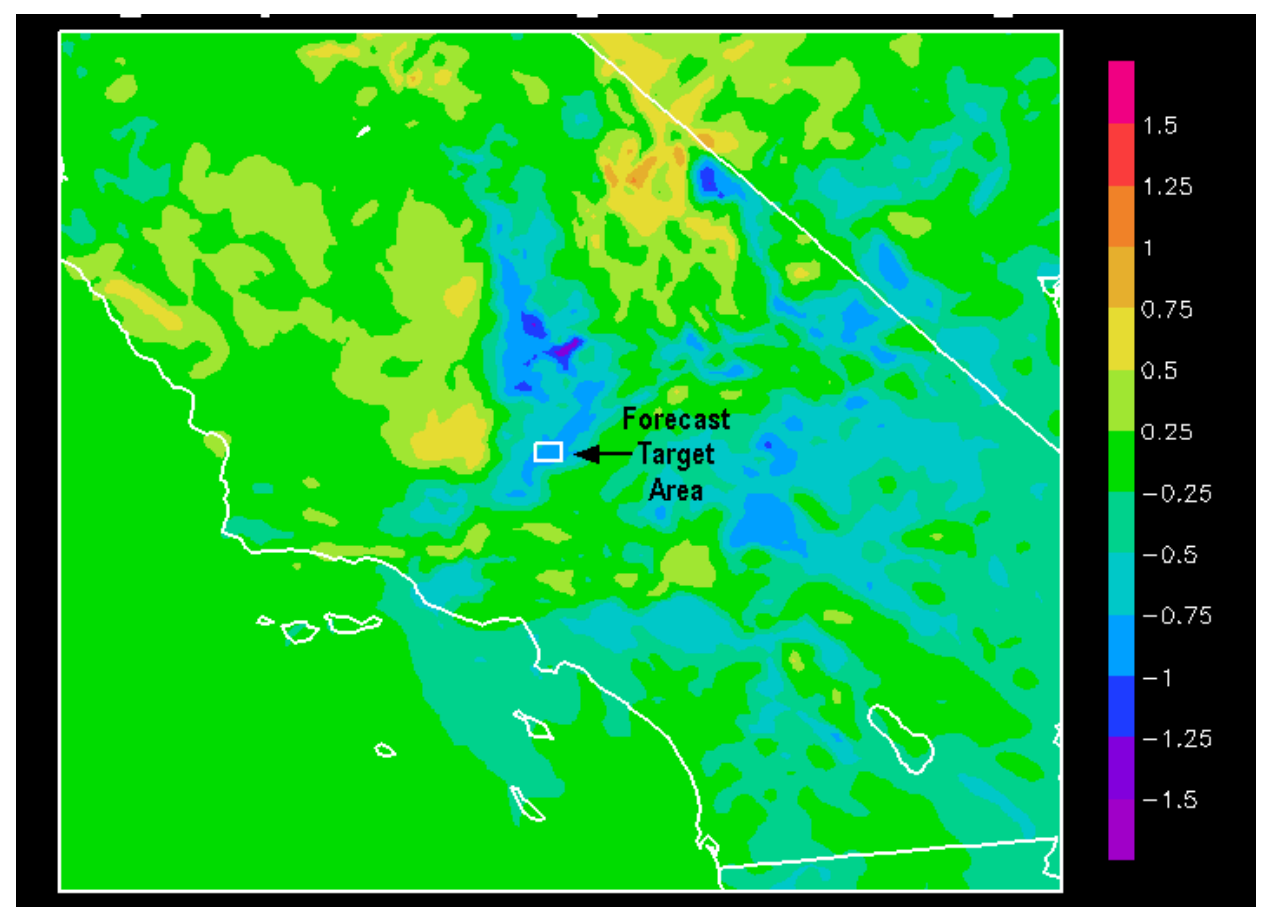

Figure 13. Average sensitivity of $80-\mathrm{m}$ wind speed $(\mathrm{m} / \mathrm{s})$ within the white target box to 25-m to 1-km AGL temperature difference throughout the entire grid domain for a 3-hour ahead forecast for all time periods in the 45-day analysis period. 


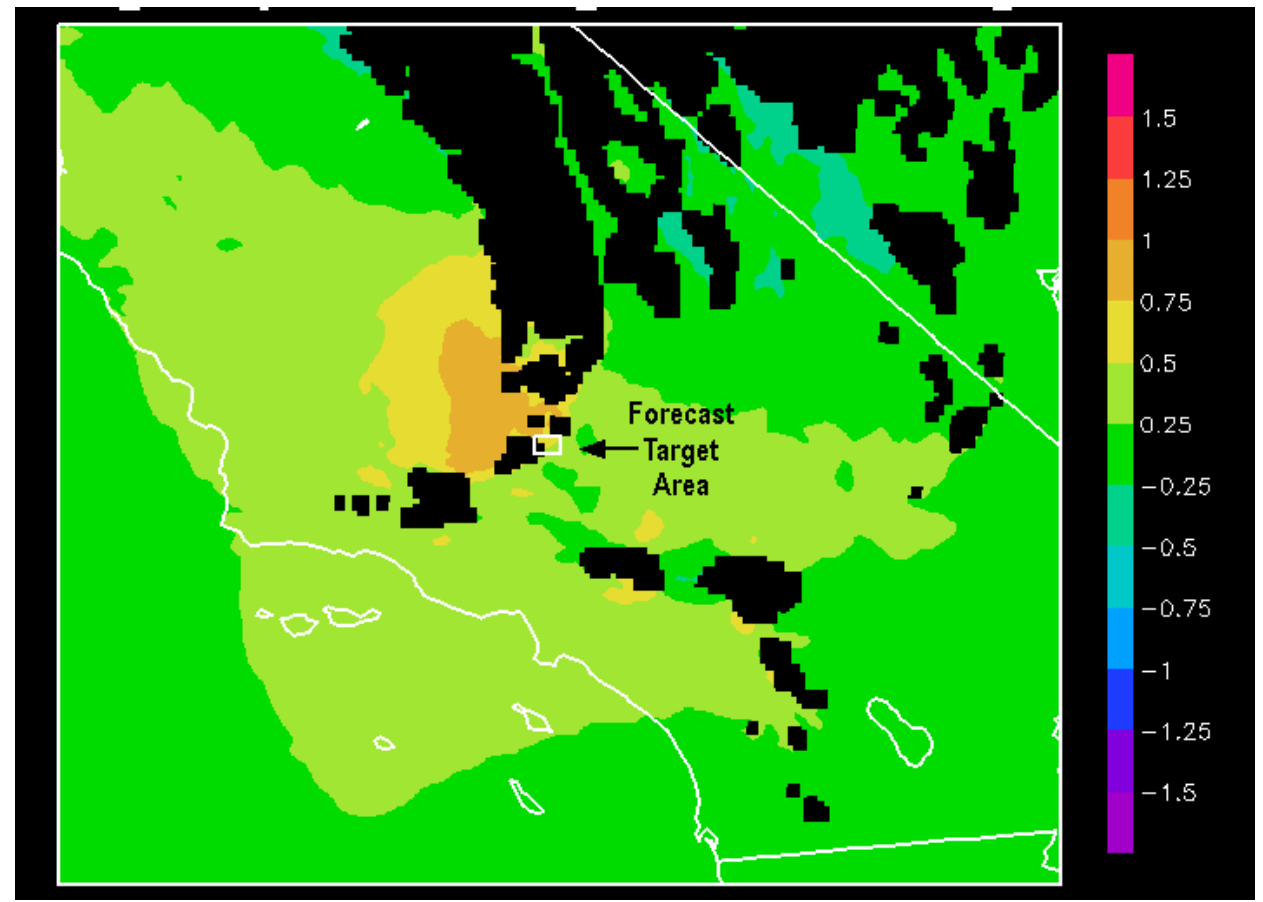

Figure 14. Average sensitivity of $80-\mathrm{m}$ wind speed $(\mathrm{m} / \mathrm{s})$ within the white target box to the $1.5-\mathrm{km}$ AMSL wind speed $(\mathrm{m} / \mathrm{s})$ throughout the entire grid domain for a 3-hour forecast for all time periods in the 45-day analysis sample.

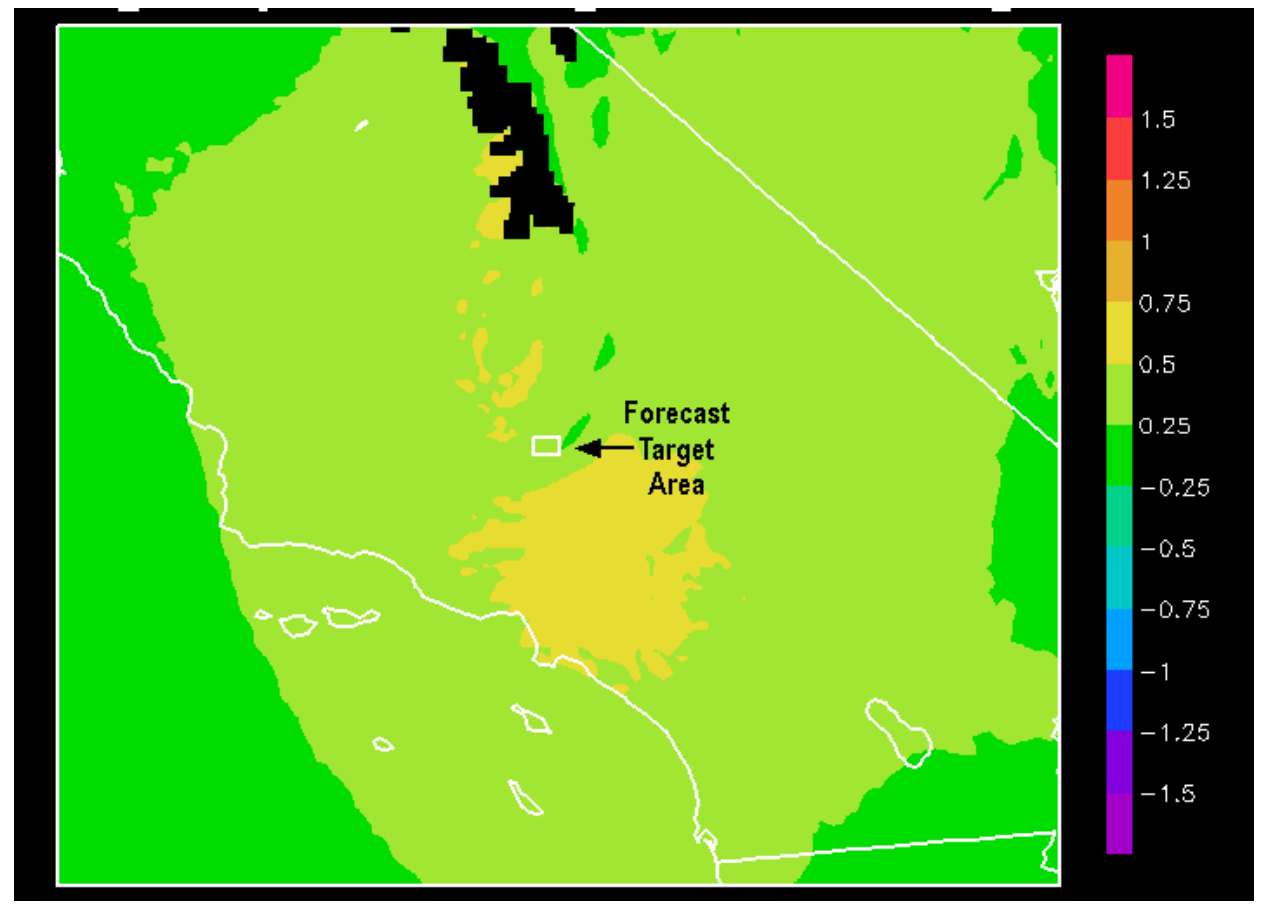

Figure 15. Average sensitivity of $80-\mathrm{m}$ wind speed $(\mathrm{m} / \mathrm{s})$ within the white target box to the northwest component of the 3-km AMSL wind speed $(\mathrm{m} / \mathrm{s})$ throughout the entire grid domain for a 3-hour forecast for all time periods in the 45-day analysis sample. 
As noted earlier, an alternative summary statistic is the frequency with which an IC variable exhibits statistically significant non-zero sensitivity at the $95 \%$ confidence level. If this criterion is satisfied for a specific grid point and time, it indicates only a $5 \%$ probability that the sensitivity was produced by random data variations drawn from a sample in which the actual sensitivity was zero. Thus it is very unlikely that the actual sensitivity is zero at that point and time. However, this statistic does not provide information about the magnitude of the sensitivity.

For the Tehachapi Pass experiment, the statistically significant non-zero sensitivity at the 95\% confidence level was computed for each forecast interval in the 45-day analysis sample. Then the fraction of the 45-day sample having non-zero sensitivity was calculated for each of the IC variables under consideration

Figure 16 illustrates the frequency of statistically significant non-zero sensitivity to the 80-m wind for a 3-hour forecast of the average $80-\mathrm{m}$ wind speed in the metric area (white box). The frequency is over $80 \%$ for the points within the metric box itself and the area of greater than $80 \%$ frequency extends along the axis of the mountain ranges on both sides of Tehachapi Pass. The highest frequency of around $90 \%$ is in the immediate vicinity of the metric box itself. The fact that the area in the vicinity of the metric box has a high frequency of statistically sensitive nonzero sensitivity but only a modest average sensitivity (Figure 12) suggests that the 80-m winds in metric box have a very persistent small sensitivity to the local values three hour earlier.

This result is consistent with the fact that the recent history of the winds in the vicinity of the wind generation facility typically has some predictive value but that the forecast value of these data sets is quite modest. The off-site locations to the north-northwest of the metric box have a much higher average sensitivity (Figure 12) and the frequency of statistically significant nonzero sensitivity is also near 70\%. The combination of high average sensitivity and high frequency of non-zero sensitivity make these among the best locations for additional measurements to improve the forecasts for a typical day in Tehachapi Pass.

There is a high frequency area of non-zero sensitivity over the Pacific Ocean to the west of the Santa Barbara but the average sensitivity in this region is quite low. There are two similar areas over the Mojave Desert to the southeast of the metric box. The one furthest to the southeast coincides with an area of low average sensitivity. The one closer to the metric box has a fairly high average sensitivity but lower than regions to the north and north-northwest (Figure 12).

The frequency of statistically significant non-zero sensitivity of the 3-hour ahead 80-m wind speed forecast to the $25-\mathrm{m}$ to $1-\mathrm{km}$ temperature difference is depicted in Figure 17 . Over the entire domain, the frequency of non-zero sensitivity to the low-level temperature difference is much lower than the frequency of non-zero sensitivity to the 80-m wind speed. However, the frequency is fairly high in the vicinity of the metric box and also along the northwest slopes of the Southern Sierra Nevada Mountains to the north-northwest of the metric box. This region also showed a large magnitude of negative sensitivity (Figure 13) and is therefore a valuable location to measure the vertical profile of temperature in the lowest kilometer of the atmosphere.

There is also a frequency maximum in the extreme southern portion of the Central Valley to the west of the metric box. The value in this area is only slightly over $50 \%$ but it is also characterized by a maximum in the magnitude of positive average sensitivity values. As a result, there may also be considerable value in measuring the vertical profile of the temperature in this region. While there are also other areas of high frequency located at greater distances from the 
metric box, many are not physically linked to the flow through the Pass on the 3-hour time scale and are merely correlated with the high frequency locations near the metric box,

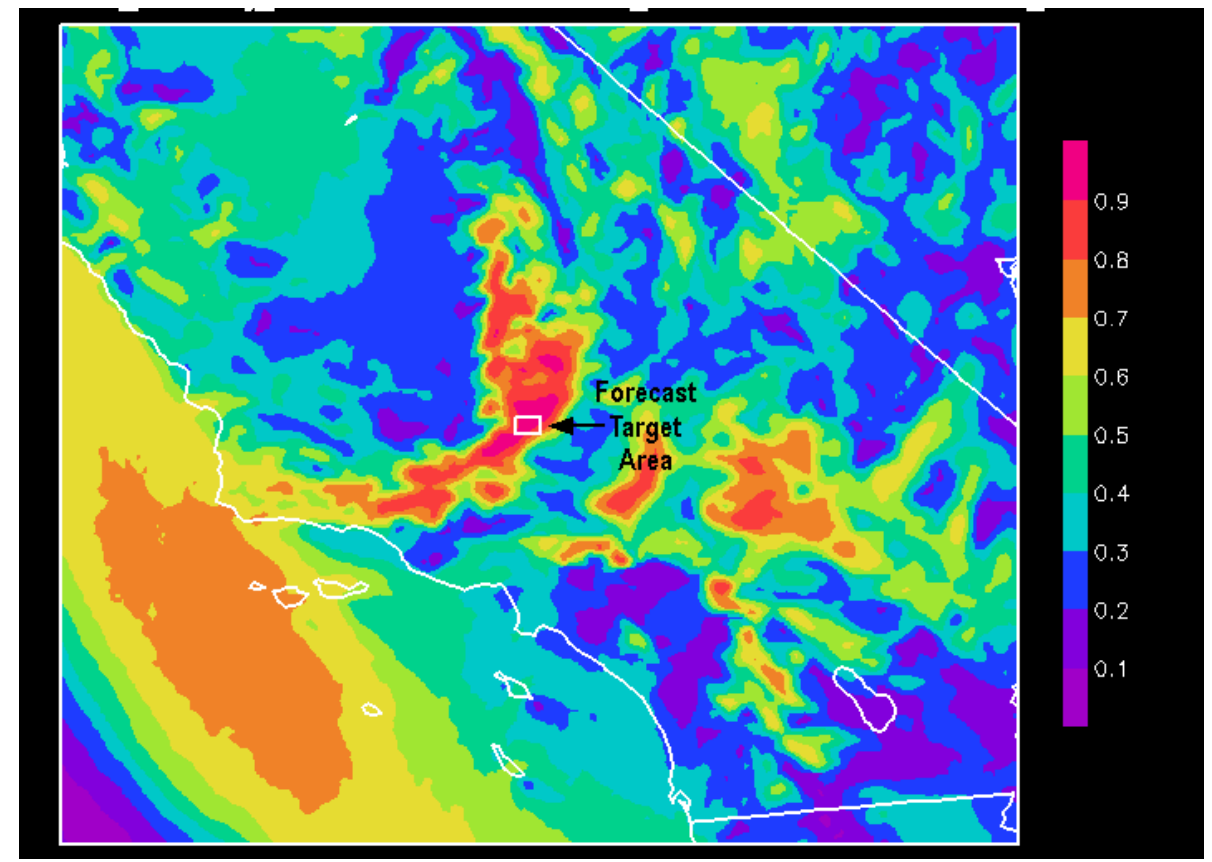

Figure 16. Frequency (fraction of time periods) of statistically significant non-zero sensitivity at the $95 \%$ confidence level of the average $80-\mathrm{m}$ wind speed in the forecast metric area (white box) to 80-m wind speed 3 hour earlier for the 45-day sample.

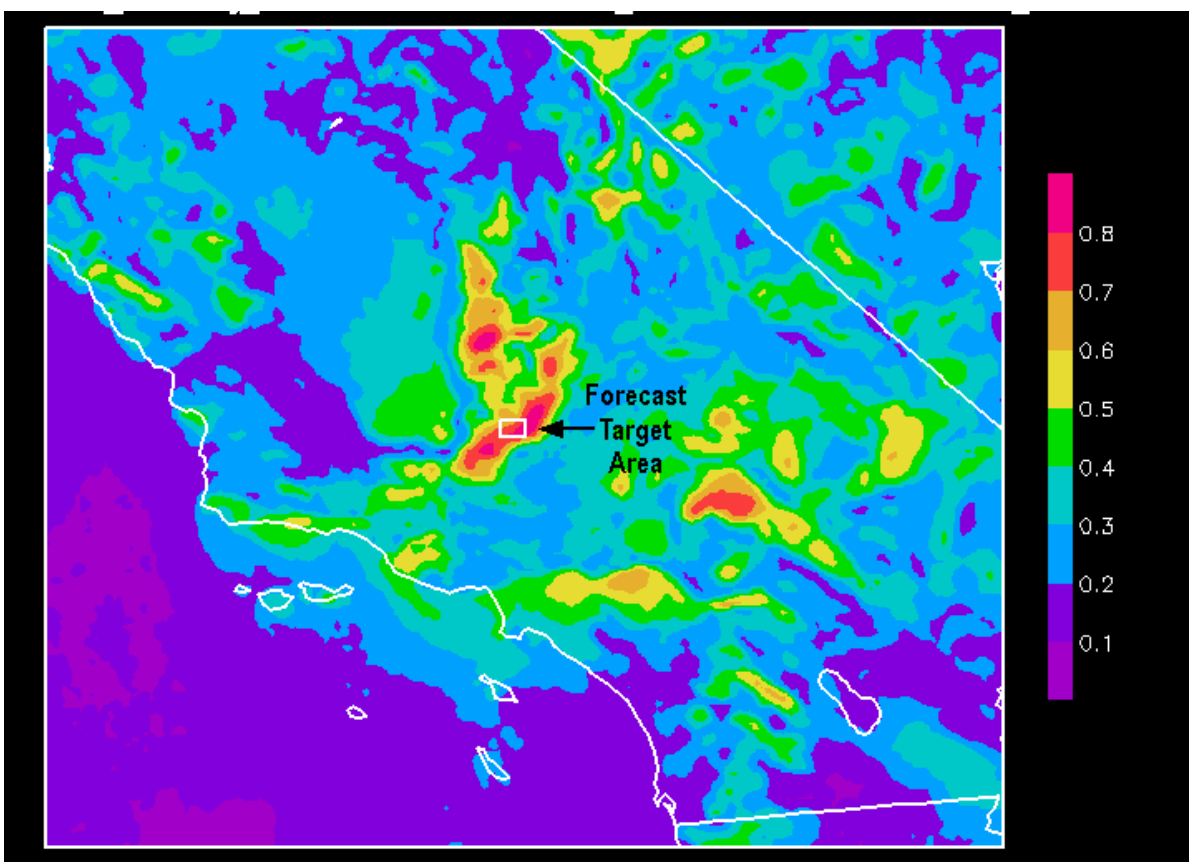

Figure 17. Frequency (fraction of time periods) of statistically significant non-zero sensitivity at the $95 \%$ confidence level of the average $80-\mathrm{m}$ wind speed in the forecast metric area (white box) to $25-\mathrm{m}$ to $1-\mathrm{km}$ AGL temperature difference 3 hour earlier for the 45-day sample. 


\subsubsection{Large Wind Ramp Subsample}

As noted earlier the impact of wind forecast errors on operations is not the same for all situations. Forecast errors during periods of large changes in wind speed and the associated wind power production (known as wind ramps) have a greater impact on grid operations than prediction errors during other time periods. In addition, the forecast errors tend to be larger in these situations since there is typically more uncertainty in the atmospheric flow patterns during periods of large change. This situation provides motivation to compile summary statistics of the forecast sensitivity for a subsample consisting of only the large ramp time periods.

The large ramp periods were defined through the use of wind power production values estimated from 5-minute wind speed data from several meteorological towers in the Tehachapi Pass area. One or two consecutive missing values in the 5-minute wind speed data series were filled in through linear interpolation. Longer periods of missing data were not filled in and omitted from the analysis. Wind speed was converted to power production as a percent of capacity using a power curve from a typical wind farm composed of 1.5-MW turbines resulting in values of $0 \%$ below $3.5 \mathrm{~m} / \mathrm{s}$. Power production increased from $0 \%$ at $3.5 \mathrm{~m} / \mathrm{s}$ to $100 \%$ at $13.5 \mathrm{~m} / \mathrm{s}$ and remained at $100 \%$ of capacity until $20 \mathrm{~m} / \mathrm{s}$ then decreased linearly to zero at $24 \mathrm{~m} / \mathrm{s}$. Power production was computed separately from the wind speed data at each meteorological tower. The individual power production values were then combined into a single aggregate number by assuming that each tower represented an equal amount of the regional capacity. Since only a few meteorological towers were used, missing data from any single tower resulted in a missing data flag being assigned to the aggregate power for that interval.

Ramp events were diagnosed on two time scales of 60 and 180 minutes. Sixty-minute ramps were located by finding the maximum change in power production over a time scale of 20 to 60 minutes that began at each 15-minute period in the data sample. The largest positive and negative changes were recorded as the 60-minute upward and downward ramp rates for that period. The 180 -minute ramps rates were computed in the same way, but used power changes over a 65 - to 180-minute period. If the start and end time for ramps from adjacent or nearby 15-minute periods overlapped to any degree, the smaller amplitude ramp was eliminated.

Next, a ramp event was defined for each 60- or 180-minute ramp rate. An event was defined as the entire contiguous period for which the 5-minute ramp rate exceeded $10 \%$ of the maximum 5minute ramp rate in the period. Once again, any overlapping ramps of the same sign were compared and the smaller one was eliminated from the sample.

Finally, ramps of each sign (up and down) and duration range (60 or 180 minutes) were examined separately to create a list of 29 large ramps. The observed wind speed and calculated power time series for each ramp were examined starting with the largest amplitude ramp. Any ramp that was a result of a brief (approximately 15-30 minutes) or shorter spike in the wind speed or seemed to be the result of erroneous interpolation of brief data gaps was not included in the list. Ramps that appeared to be the result of a coherent and persistent change in the power were included. This process continued until there were 7 to 8 ramps of each type (i.e. up, down, 60-minute, 180-minute) in the list. The resulting list of 29 ramp events is presented in Table 1. 
Table 1. List of large ramp events used to define the ramp subsample for the sensitivity analysis.

\begin{tabular}{|c|c|c|c|}
\hline $\begin{array}{c}\text { Start Time } \\
\text { (YYYY MMDD HHmm) } \\
\text { (UTC) }\end{array}$ & $\begin{array}{c}\text { Amplitude } \\
\text { (\% Capacity) }\end{array}$ & $\begin{array}{c}\text { Maximum 5- } \\
\text { minute ramp rate } \\
(\% \text { Capacity }) \\
\end{array}$ & $\begin{array}{l}\text { Duration } \\
\text { (minutes) }\end{array}$ \\
\hline \multicolumn{4}{|c|}{ Upward Ramps } \\
\hline 200807122320 & 79.5 & 0.225 & 140 \\
\hline 200808091820 & 79.3 & 0.183 & 165 \\
\hline 200807092045 & 78.5 & 0.392 & 170 \\
\hline 200807152005 & 77.6 & 0.216 & 150 \\
\hline 200808150020 & 77.6 & 0.233 & 180 \\
\hline 200807260050 & 76.2 & 0.152 & 165 \\
\hline 200807232155 & 72.1 & 0.308 & 180 \\
\hline 200807262015 & 69.6 & 0.129 & 175 \\
\hline 200807161925 & 69.5 & 0.135 & 140 \\
\hline 200807082220 & 56.3 & 0.173 & 50 \\
\hline 200807141940 & 54.4 & 0.293 & 60 \\
\hline 200807120255 & 51.2 & 0.148 & 60 \\
\hline 200808212305 & 48.0 & 0.269 & 55 \\
\hline 200808222330 & 43.5 & 0.170 & 60 \\
\hline 200807182055 & 43.2 & 0.121 & 60 \\
\hline \multicolumn{4}{|c|}{ Downward Ramps } \\
\hline 200808031445 & -83.8 & -26.2 & 150 \\
\hline 200807130140 & -79.4 & -31.2 & 150 \\
\hline 200808171030 & -74.2 & -15.2 & 180 \\
\hline 200807281620 & -67.8 & -17.6 & 180 \\
\hline 200807231335 & -66.5 & -52.3 & 175 \\
\hline 200808201535 & -64.7 & -20.4 & 180 \\
\hline 200807271235 & -63.4 & -33.5 & 140 \\
\hline 200808221325 & $\begin{array}{l}-63.1 \\
\end{array}$ & -15.1 & 190 \\
\hline 200808090110 & -63.0 & -15.2 & 145 \\
\hline 200808200040 & -53.1 & -25.2 & 60 \\
\hline 200808150445 & -49.5 & -40.2 & 60 \\
\hline 200808111215 & -49.4 & -11.3 & 60 \\
\hline 200808151525 & -44.3 & -8.6 & 60 \\
\hline 200807140320 & -40.9 & -10.2 & 65 \\
\hline
\end{tabular}

The average sensitivity of a 3-hour forecast of 80-m wind speed to each of the ten IC variables considered in this investigation was computed over the 3-hour forecast intervals that bracketed the start times of the large ramp events. Therefore, the forecast metric time was either during or after the event while the initial condition time was prior to the start of the event. A depiction of the geographical patterns for three most sensitive IC variables is presented in Figures 18 through 20 .

The average sensitivity to the 80 -m wind speed three hours earlier is shown in Figure 18 and is analogous to the average sensitivity over all time periods in the 45 -day sample (Figure 12). It can 
be seen that the average sensitivity to $80-\mathrm{m}$ wind speed for the ramp event subsample is quite similar to the average sensitivity for all time periods in the 45-day analysis period. The area of highest sensitivity stretches northward from Tehachapi Pass on the northwest side of the Southern Sierra Nevada Mountains.

The average sensitivity of 3-hour ahead forecasts of the $80-\mathrm{m}$ wind speed to the $25-\mathrm{m}$ to $1-\mathrm{km}$ temperature difference for the ramp event cases is shown in Figure 19. This map is analogous to the average sensitivity for the entire 45-day sample shown in Figure 13. The ramp event cases are characterized by a sharper gradient between the negative sensitivity areas over the mountains to the north of Tehachapi Pass and the positive sensitivity area in the Central Valley to the northwest of the Pass. A stronger gradient is found because the positive sensitivity area in the Central Valley covers a broader area and has a larger magnitude.

The average sensitivity to the northwest component of the $1.5-\mathrm{km}$ wind speed for the ramp event time periods is shown in Figure 20. The corresponding depiction for the full 45-day sample is presented in Figure 14. This comparison indicates that the magnitude of the maximum average sensitivity for the ramp event cases is similar to the magnitude of the maximum for the full 45day sample but the area of high sensitivity is much larger for the ramp event cases. For the ramp event time periods, the area of high sensitivity extends northward well into the Central Valley.

Several factors should be considered when analyzing the sensitivity composites for the ramp event cases. First, the selection of cases was based upon observed ramp events inferred from actual anemometer data from the southern portion of Tehachapi Pass. However, it is not certain that all or even some members of the simulation ensemble had equivalent ramp events during the same time windows. It is certainly possible (even likely) that the errors in the timing of the events in all or some of the ensemble members were large enough to move the event outside the forecast window (i.e. outside the 3-hour window between the IC variable time and the forecast) used to analyze the sensitivity for each case.

In other cases, it is possible that the simulation ensemble (or a large fraction of it) completely missed the event. In either case, the sensitivity computed for that event may not be representative of the time period associated with a ramp event. It would be necessary to diagnose the ramp events contained in the time series of simulated data and compare the timing and amplitude with those for observed events. This analysis was beyond the scope of the current effort but would reveal how well the simulated data for these time periods represented ramp events.

The second factor that should be considered is that the ramp event sample consisted of both upward and downward ramps as well as 60-minute and 180-minute events In fact, the numbers of each type of event (up or down, short or long) included in the sample were approximately equal and therefore not dominated by any one type. However, it is likely that the flow patterns associated with each of these types of ramp events have different characteristics. Therefore, it is a reasonable expectation that the sensitivity pattern for each type of event may have significant characteristics that are different from the other types of events. The fact that all four types of events were included in the sample in approximately equal numbers suggests that unique sensitivity characteristics were likely lost in the averaging process. 


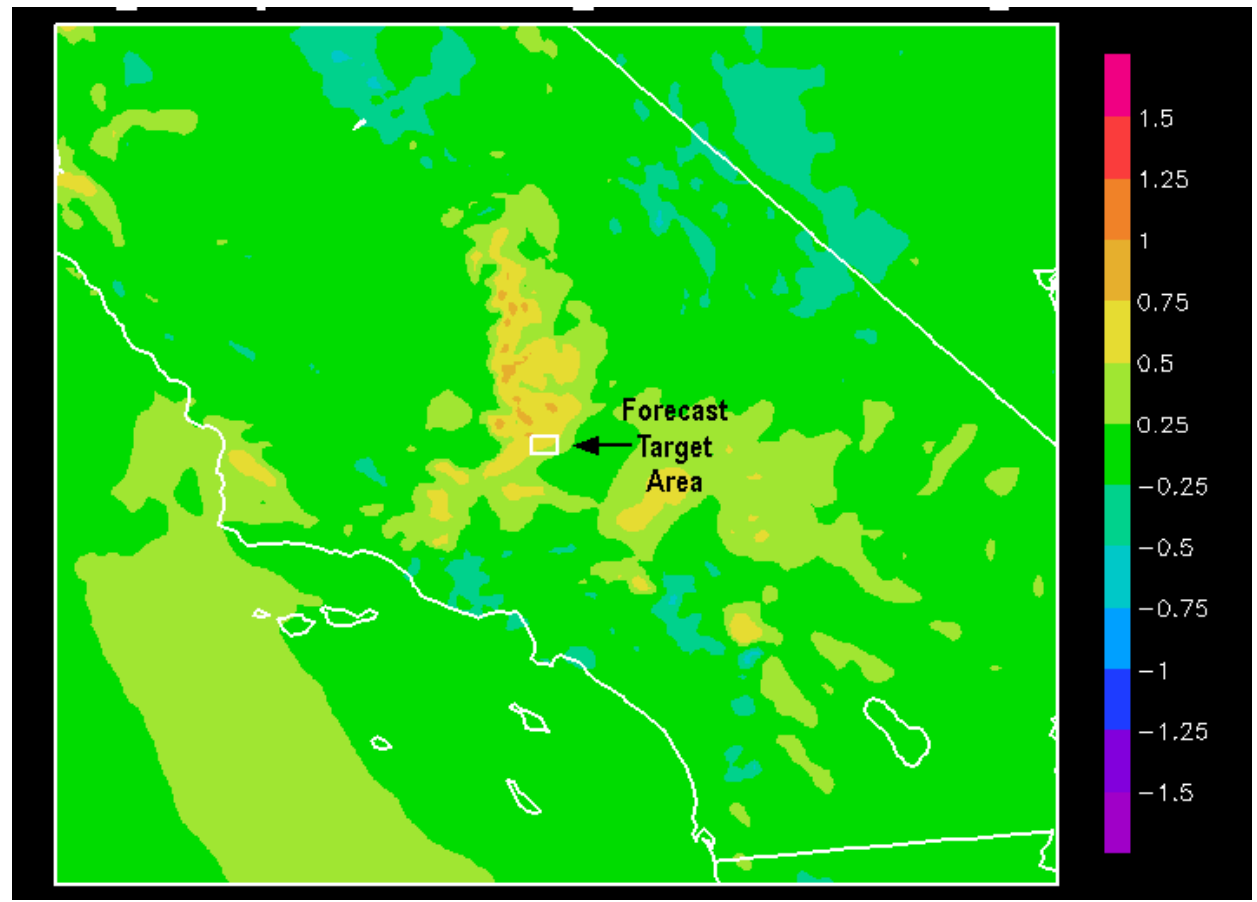

Figure 18. Average sensitivity values of $80-\mathrm{m}$ wind speed $(\mathrm{m} / \mathrm{s})$ within the white target box to the 80-m wind speed throughout the entire grid domain for a 3-hour look-ahead period for the ramp event time periods listed in Table 1.

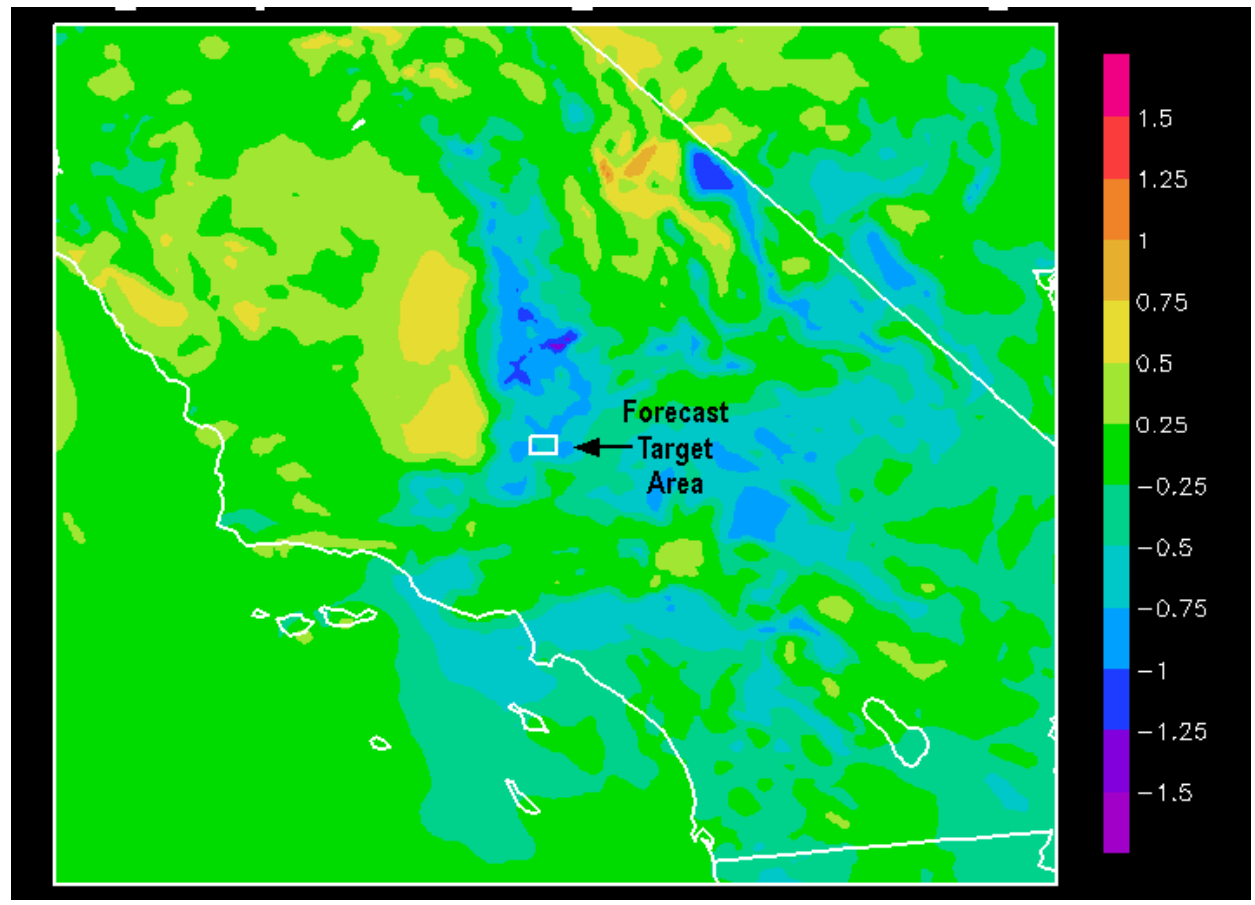

Figure 19. Average sensitivity values of $80-\mathrm{m}$ wind speed $(\mathrm{m} / \mathrm{s})$ within the white target box to the $25-\mathrm{m}$ to $1-\mathrm{km}$ temperature difference throughout the entire grid domain for a 3-hour look-ahead period for the ramp event time periods listed in Table 1. 


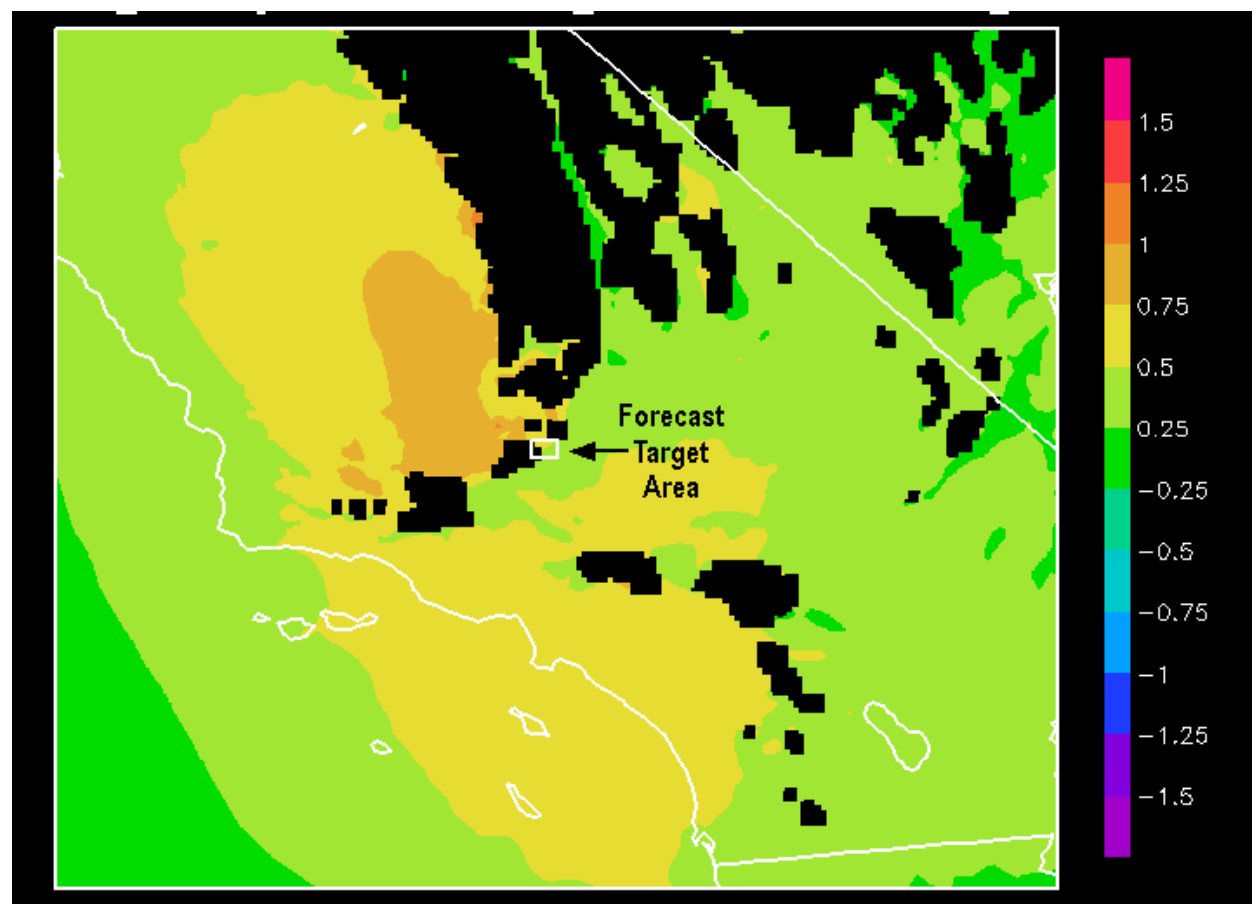

Figure 20. Average sensitivity values of $80-\mathrm{m}$ wind speed $(\mathrm{m} / \mathrm{s})$ within the white target box to the northwest ( Pass-parallel) component of the $1.5-\mathrm{km}$ wind speed throughout the entire grid domain for a 3-hour look-ahead period for the ramp event time periods listed in Table 1. 


\subsection{Strategy for Determining an Optimal Set of Variables and Locations}

The forecast sensitivity dataset can be used to select a combination of locations and variables that will provide the most improvement for the prediction of the forecast metric over the desired look-ahead period. The simplest and most obvious way to do that is to select the location of the maximum average sensitivity for each IC variable considered. However, the direct use of these points would likely not yield an optimal solution because the IC variables, in general, have a significant degree of correlation. Therefore, even though a number of variables may exhibit a high degree of sensitivity, much of the "predictive" information in each variable is highly correlated with the information in other variables. Therefore, many of the highly sensitive variables/locations essentially provide redundant information about the variability of the forecast metric for a given look-ahead period.

In order to address this issue, a procedure, termed Multiple Observation Optimization Algorithm (MOOA), was formulated to determine the relative predictive value of different combinations of variables/locations. In this procedure, a small set of variables/locations are selected by a separate algorithm and then multiple linear regression is performed on all combinations of variables/locations within that set. The variables are normalized prior to the regression. The normalization permits the regression coefficients to be used as an indicator of the relative importance of each variable when used in a combination. The $\mathrm{R}^{2}$ values of each multiple regression can also be used as an indicator of which combinations and individual variables/locations have the most value for a given forecast look-ahead period.

This approach was applied to the forecast sensitivity data generated for Tehachapi Pass. Separate calculations were performed for the full 45-day sample and the ramp-event subsample. In this application, the initial selection criterion was the location of the maximum 45-day average sensitivity for each of the three variables under consideration: (1) 80-m wind speed, (2) the 1.5$\mathrm{km}$ AMSL northwest wind component and (3) the $25-\mathrm{m}$ to $1-\mathrm{km}$ temperature difference (i.e. lapse rate). In general, the locations of maximum average sensitivity are quite similar for the full sample and the subsample (Figure 21). They are generally in the complex terrain to the north of the Tehachapi Pass metric box. The locations for the two wind variables are to the west of the location for the boundary layer lapse rate variable. The $3-\mathrm{km}$ wind speed variable was not considered in this analysis because its normalized sensitivity was much lower than that of the other three variables and consequently it did not increase the $\mathrm{R}^{2}$ nearly as much as the other three variables.

Once this set of variables/locations was selected, multiple linear regression was performed on all combinations of variables/locations separately for the full sample and the ramp event subsample. The $\mathrm{R}^{2}$ values for the resulting regression equations are listed in Table 2. Among the single variable regressions, the $80-\mathrm{m}$ wind speed had the highest $\mathrm{R}^{2}$ value, indicating that this is the best single variable/location to measure. However, the $\mathrm{R}^{2}$ values for the other two single variable regressions were only modestly lower, which suggests that they might add additional predictive value. Indeed, all of the two-variable regressions had a substantially higher $\mathrm{R}^{2}$ value than the best single variable regression. The combination of $80-\mathrm{m}$ wind speed and the $25-\mathrm{m}$ to $1-\mathrm{km}$ temperature difference produced the highest two-variable $\mathrm{R}^{2}$ value for both the full 45 -day sample and the ramp event subsample. This result indicates that among the variables/locations considered, these would be the best choice to measure. The combination of upstream $80-\mathrm{m}$ wind 
speed and the lapse rate in the layer above the Pass is physically quite reasonable since flow through the Pass is strongly modulated by the speed of the wind entering the Pass and the stability of the air above the Pass.

The results from the three-variable regression indicate that the additional value in measuring the $1.5-\mathrm{km}$ northwest wind component is much more modest than adding the second variable. For the full sample, the average $\mathrm{R}^{2}$ value increased by 0.041 over the best two-variable regression. and 0.038 for the ramp event subsample suggesting that the third variable does provide some additional useful information.

The results in Table 2 only represent the average $\mathrm{R}^{2}$ for all the time periods in the respective sample. However, the $\mathrm{R}^{2}$ values actually vary substantially among the time periods in the sample from a high of about 0.62 to a low of slightly under 0.15 (Figure 22). A similar degree of variability was found in the full 45-day sample. Thus, it is evident that the forecast metric is substantially more sensitive to this combination of variables/locations for some time periods then it is for other time periods.

In addition to the variability in the three-variable $\mathrm{R}^{2}$ within the ramp-event sample, there was also a considerable variability in the relative contributions of each variable/location (Figure 23). As noted earlier, the variables have been normalized so the magnitude of the coefficients is a direct indication of the relative influence of each variable on the overall relationship. None of the individual variables consistently dominate the relationship. The $80-\mathrm{m}$ wind speed variable is dominant for some time periods (e.g. 23 July 2100 UTC) but the lapse rate and 1.5-km wind variables have a dominant influence at other times (e.g. 15 August 0600 UTC). In some cases, all three variables have nearly equal influence (e.g. 9 August 0300 UTC)
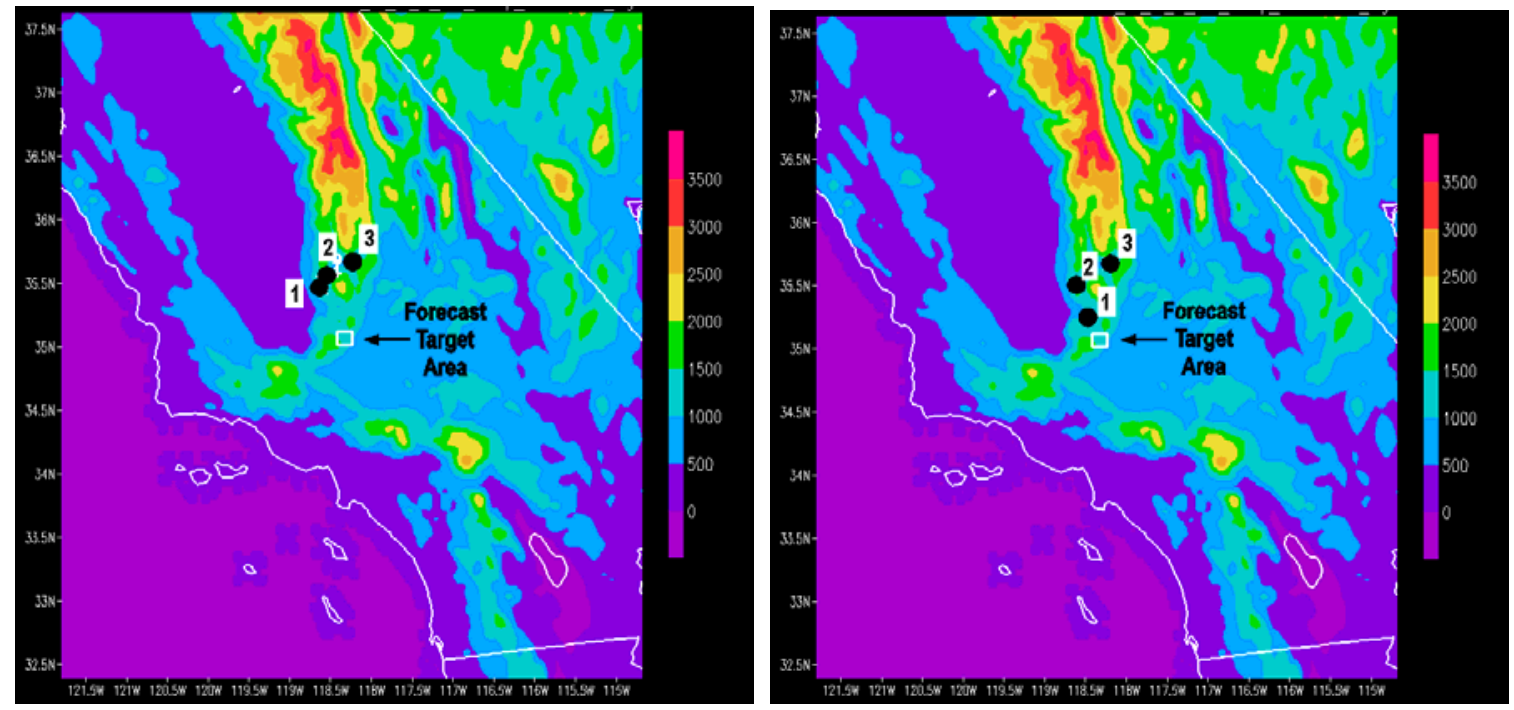

Figure 21. Locations of the points of maximum average 45-day sensitivity for a 3-hour forecast of the average $80-\mathrm{m}$ wind speed over an area on the southeastern side of Tehachapi Pass (white box) for three initial condition variables: (1) 80-m wind speed, (2) northwest component of the 1.5-km AGL wind speed and (3) the $25-\mathrm{m}$ to $1-\mathrm{km}$ temperature difference. The color shading depicts the elevation $(\mathrm{m})$ of the model terrain above sea level. 
Table 2. Average $\mathrm{R}^{2}$ value for 1, 2 and 3 variable sensitivity regression for a 3 -hour forecast of the 80-m wind speed in the forecast metric target area in the southeastern portion of Tehachapi Pass (white box in Figure 20) for all time periods and only the ramp periods.

\begin{tabular}{|l|c|c|}
\hline \multicolumn{1}{|c|}{ IC Variables } & All Periods & Ramp Periods \\
\hline \multicolumn{3}{|c|}{ One Variable } \\
\hline (1) $80-\mathrm{m}$ wind speed & 0.287 & 0.249 \\
\hline (2) 1.5-km AMSL northwest wind component & 0.216 & 0.212 \\
\hline (3) $25-\mathrm{m}-1-\mathrm{km}$ temperature difference & 0.219 & 0.203 \\
\hline \multicolumn{3}{|c|}{ Two Variables } \\
\hline (1) and (2) & 0.357 & 0.324 \\
\hline (1) and (3) & 0.371 & 0.358 \\
\hline (2) and (3) & 0.325 & 0.325 \\
\hline \multicolumn{3}{|c|}{ Three Variables } \\
\hline (1), (2) and (3) & 0.412 & 0.396 \\
\hline
\end{tabular}

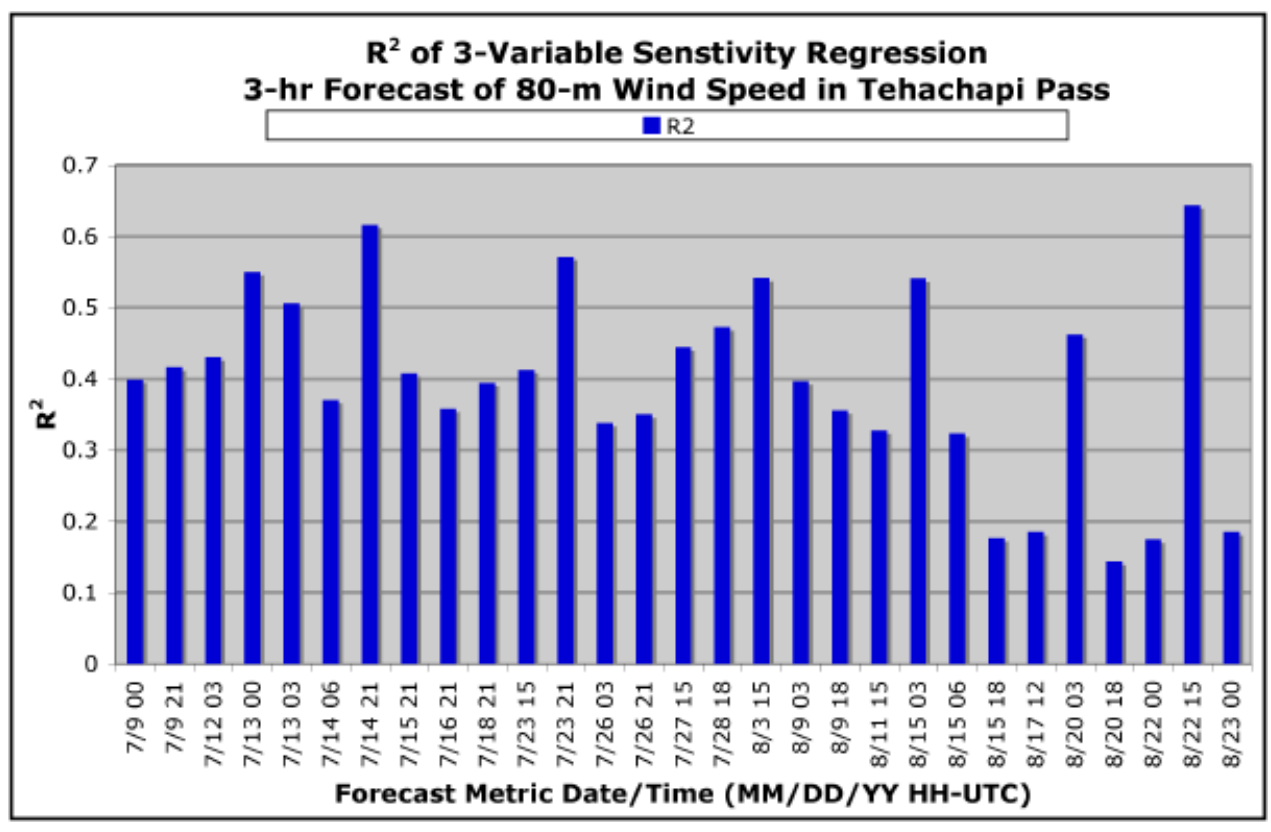

Figure 22. $\mathrm{R}^{2}$ value for a multiple regression of three normalized IC variables from their respective points of maximum average 45-day sensitivity (locations depicted in Figure 20) for a 3 -hour forecast of the average $80-\mathrm{m}$ wind speed in the Tehachapi Pass metric box for each of 29 ramp events. 


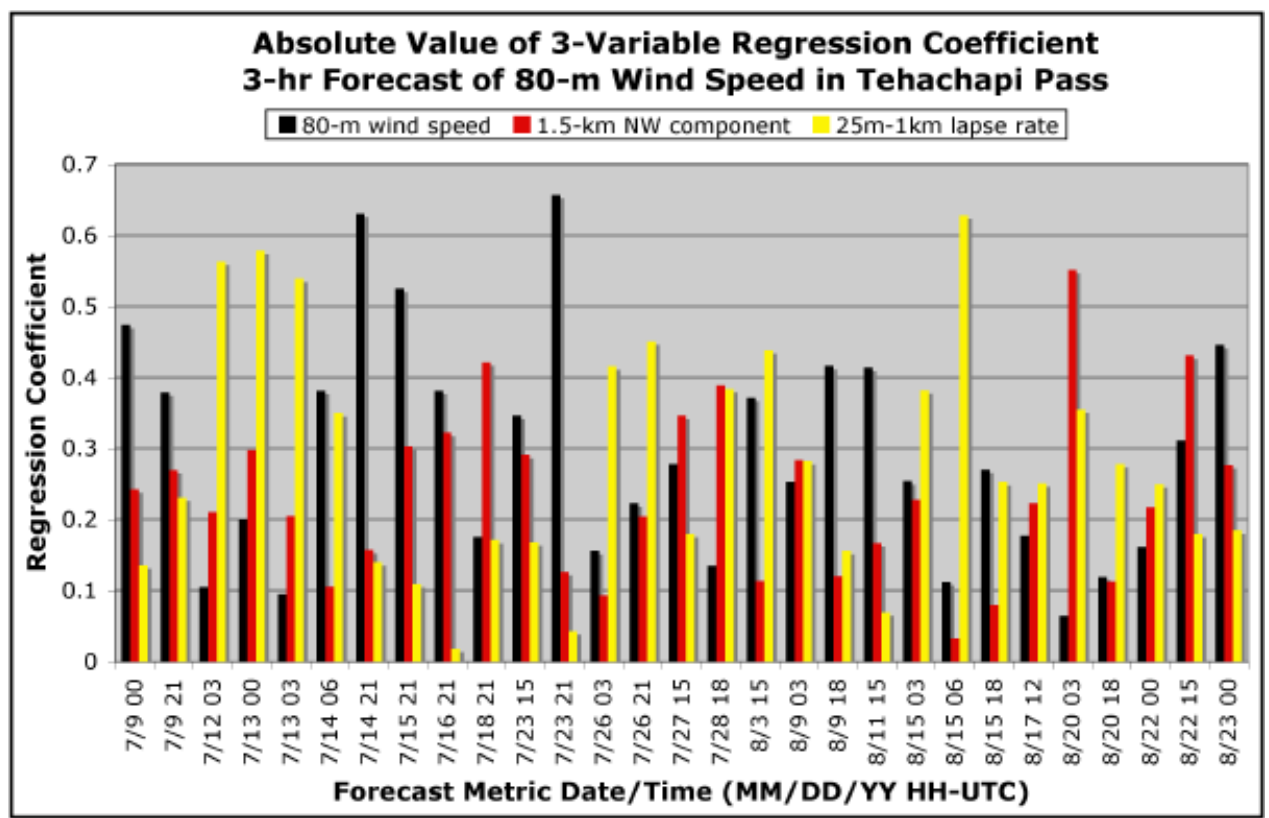

Figure 23. Absolute value of the regression coefficient for combinations of three normalized IC variables from their respective points of maximum average 45-day sensitivity (locations depicted in Figure 20) for a 3-hour forecast of the 80-m wind speed in the Tehachapi Pass metric box for each of 29 ramp events.

The multiple variable/location analysis suggests that it is necessary to utilize all three of the identified variables/locations in order to achieve consistent value for the ramp event cases. However, there is likely more information to be extracted from the sensitivity dataset given that several factors were not considered in this preliminary analysis.

First, the analysis did not account for the fact that the there may be other locations (with less than the maximum sensitivity) of the same variable that have more value in a combination than the location of maximum sensitivity of an additional (i.e. different) variable. For example, a second $80-\mathrm{m}$ measurement may increase the $\mathrm{R}^{2}$ of a multi-variable regression more than the stability parameter measured at the point of maximum sensitivity. Therefore, it would be useful to include multiple points from each variable in the final analysis rather than just the point of maximum sensitivity.

A second factor is the issue of whether the point of maximum average sensitivity is the best initial location to select for a particular variable. It is clear from an examination of the sensitivity fields for individual time periods that the location of maximum sensitivity varies substantially among the time periods in the analysis sample. Thus for some cases, the point of maximum average sensitivity is actually a low sensitivity point. The root question is how to best combine information from the sensitivity fields for the individual time periods into an aggregated field that provides the best guidance on which point to select. For example, instead of using the average sensitivity, the frequency of significant sensitivity for a particular confidence level could be employed as the basis for the selection of a candidate observation point for a particular variable. This method would select a point having the most frequent occurrence of non-zero sensitivity but would not necessarily be the point frequently close to the highest sensitivity value. 
There are many other summary statistics that could be used as the basis for selecting the observation point and these can be explored in extensions of the current effort.

A third issue is the set of ten variables considered in the current analysis. These particular ones were selected based on experience with the physics of the Tehachapi Pass wind patterns and variables that have the potential to be measured at high temporal frequency and modest cost with current technology. It is certainly possible that the forecast metric could have a higher sensitivity to other basic or derived variables not considered here as part of the single or multivariate analysis.

A final issue is the representativeness of the period used for the ESA as the wind regimes in Tehachapi Pass are quite different in the summer versus the winter. From a wind energy perspective, the warm season is much more important since a disproportionate fraction of the power generation occurs during the warm season and the demand for power in California is much greater during that time of year. As a result, management of the electric grid is more sensitive to short-term wind energy forecasts in the warm season. A related issue is that the frequency of weather regimes (e.g. easterly versus westerly flow) in any season varies from year to year and thus it would be useful to expand the warm season sample by including cases from other years.

It is also important to note that the forecast sensitivity fields and the observation deployment strategies derived from them were not validated in this study. These issues could be addressed by observation denial experiments using data gathered at the targeted locations or observing system simulation (OSSEs) experiments (e.g. Kalnay et al. 1985; Arnold and Dey 1986). Such validation is essential before using the ESA approach as a routine tool for the formulation of senor network deployment strategies intended to improve the very short-term forecasting of wind power production. 


\section{Summary}

A recently formulated approach called Ensemble Sensitivity Analysis (ESA), which is designed to analyze the sensitivity of forecasts to changes in the prior values of atmospheric state variables, was applied to short-range forecasts of the $80-\mathrm{m}$ wind speed in the Tehachapi Pass of California. The method is based on the statistical analysis of data from a relatively large ensemble of NWP model simulations for an analysis period that is representative of the weather regimes in the area of interest. The members of the ensemble differ from each other due the introduction of perturbations in the initial and boundary conditions of the numerical atmospheric simulations. The introduction of the perturbations permits an analysis of the sensitivity of a forecast for a selected metric and look-ahead period to prior values of atmospheric state variables for individual dates and times. One or more types of composites (e.g. averages) of the forecast sensitivity parameters for individual dates and times can then be generated to provide information about the climatological sensitivity patterns. These composite patterns can, in turn, be used as guidance on where to deploy meteorological sensors to achieve the greatest impact on forecast performance for the desired variable and look-ahead period. This method has previously been applied to large-scale weather prediction but not to short-term wind forecasting.

The ESA approach was applied to Tehachapi Pass through the use of the WRF 2.2 atmospheric model and DART data assimilation software. This software system was used to execute an ensemble of 48 members over a period that extended from 1200 UTC 7 July to 1200 UTC 24 August 2008. The first day and a half was considered to be a spin-up period for the ensemble and was excluded from the forecast sensitivity calculations. Output was saved every hour and the forecast sensitivity for 1- to 6-hour look-ahead periods was computed from the hourly output data. Ten prior state variables were considered in the analysis. The forecast sensitivity was computed for all time periods in the sample as well as a ramp event subsample. The ramp-event subsample consisted of 29 time periods in which large changes (up or down) in wind power production occurred in a 3 -hour or shorter period.

The forecast sensitivity patterns derived from the dataset were characterized by well-defined, localized patterns of high sensitivity for a number of prior state variables. The patterns were coherent and consistent with the existing knowledge of the basic physical processes that drive the wind patterns in the Tehachapi area. The most consistently sensitive variables for the Tehachapi Pass forecast target area were (1) the 80-m wind speed; (2) the 25-m to 1-km temperature difference and (3) the 1.5-km AMSL Pass-parallel (northwest) wind component.

The ESA approach developed by previous investigators was designed to produce spatial fields of forecast sensitivity for a set of prior state variables selected by the user. However, no strategy for determining the optimal combination of multiple variable-location combinations had been developed in the studies published previously. Thus, in order to provide specific guidance for the design of a network of multiple sensors and locations, MOOA was developed to determine the optimal combination of measurement locations and variables from the multitude of correlated sensitivity patterns.

The application of the MOOA to the forecast sensitivity data indicated that the $80-\mathrm{m}$ wind speed at a location the north-northwest of Tehachapi Pass was the most sensitive variable and location out of those considered. The second most sensitive variable and location was the $25-\mathrm{m}$ to $1-\mathrm{km}$ temperature difference also at a location to the north-northwest of the Tehachapi Pass wind generation area. The results of the MOOA suggest that the optimal measurements for improving 
the forecast of 80-m wind speed in Tehachapi Pass are 80-m wind speed, low-level temperature difference, and 1.5-km pass-parallel wind component at locations to the north-northwest of the Tehachapi Pass wind generation area.

The results demonstrate that the ESA method can produce physically consistent forecast sensitivity results on mesoscale space and time scales and be used to provide specific and physically reasonable guidance for the design of sensor networks intended to improve the performance of forecasts for specific variables (forecast metrics) and locations (forecast target areas). However, forecast sensitivity fields and the observation deployment strategies derived from them were not validated in this study. These issues could be addressed by observation denial experiments using data gathered at the targeted locations or observing system simulation (OSSEs) experiments.

There are number of possibilities to extend the pioneering work done in this study. As noted above, a validation of the sensitivity fields and selected targeted observation locations is needed

to establish a higher level of confidence in this approach for the mesoscale observation targeting application.

In addition, the analysis could be extended to other times of the year in Tehachapi pass or applied to other locations by using a 45-day sample in each season to approximate a climatology of sensitivity for the entire year and each of the four major seasons.

The analysis could also be expanded to include other prior state variables in addition to the ten considered identified in this study. Finally the MOOA could be enhanced to consider multiple locations from each prior state variable instead of just the maximum sensitivity points considered here.

\section{Acknowledgements}

LLNL-TR-424442: This work was performed under the auspices of the U.S. Department of Energy by Lawrence Livermore National Laboratory under Contract DE-AC52-07NA27344. The work of the AWS Truewind authors was performed under subcontract B579620 from Lawrence Livermore National Laboratory. 


\section{References}

Ancell, B. and G. J. Hakim, 2007: Comparing adjoint- and ensemble-sensitivity analysis with applications to observation targeting. Mon. Wea. Rev., 135, 4117-4134.

Anderson, J. L., 2001: An ensemble adjustment Kalman filter for data assimilation. Mon. Wea. Rev., 129, 2884-2903.

Anderson, J. L., 2007: An adaptive covariance inflation error correction algorithm for ensemble filters. Tellus, 59A, 210-224.

Anderson, J. L., and S. L. Anderson, 1999: A Monte Carlo implementation of the nonlinear filtering problem to produce ensemble assimilations and forecasts. Mon. Wea. Rev. 127, 27412758 .

Anderson, J. L., T. Hoar, K. Raeder, H. Liu, N. Collins, R. Torn, and A. F. Arellano, 2009: The Data Assimilation Research Testbed: A community data assimilation facility. Bull. Amer. Meteor. Soc., 90, 1283-1296.

Arnold, C.P. Jr., and C.H. Dey, 1986: Observing-system simulation experiments: Past, present, and future. Bull. Amer. Meteor. Soc., 67, pp. 687-695.

Errico, R. M., 1997: What is an adjoint model? Bull Amer. Meteor. Soc., 78, 2577-2591.

Errico, R. M., and T. Vukicevic, 1992: Sensitivity analysis using an adjoint of the PSU-NCAR mesoscale model. Mon. Wea. Rev., 120, 1644-1660.

Kalnay, E., R. Atlas, and M. Halem, 1985: The impact of satellite temperature sounding and wind data on numerical weather prediction. Optical Engineering, 24, 341-346.

Lin, Y-L, and I. Jao, 1995: A numerical study of flow circulations in the central valley of California and formation mechanisms of the Fresno eddy, Mon. Wea. Rev., 123, 32283239.

Torn, R. D., and G. J. Hakim, 2008: Ensemble-based sensitivity analysis. Mon. Wea. Rev., 136, 663677.

Skamarock, W. C., J. B. Klemp, J. Dudhia, D. O. Gill, D. M. Barker, W. Wang and J. G. Powers, 2005: A Description of the Advanced Research WRF Version 2, NCAR TECHNICAL NOTE: NCAR/TN-468+STR, National Center for Atmospheric Research, Boulder, Colorado, USA.

Watson, L., W. H. Bauman, and B. Hoeth, 2009: Weather Research and Forecasting model wind sensitivity study at Edwards Air Force Base, CA, Online 13th Conference on Integrated Observing and Assimilation Systems for Atmosphere, Oceans, and Land Surface IOASAOLS), available at http://ams.confex.com/ams/pdfpapers/144873.pdf. 


\section{Appendix A, Specifications of the ESA Configuration}

Table A-1. Configuration of the WRF 2.2 model and grid used in this investigation

\section{Grid}

- Matrix Size (NX, NY, NZ): 200 X 200 X 38

- Grid cell size: $\sim 4 \mathrm{~km}$

\section{Model Configuration}

- WRF single-moment (WSM) 3-class ice scheme

- Long wave radiation scheme: Rapid radiative transfer model

- Short wave radiation scheme: Dudhia scheme

- Boundary layer scheme: YSU scheme

- No convective Parameterization

- 20 -second time step

- Runge-Kutta $3^{\text {rd }}$-order time integration

- Horizontal Smagorinsky $1^{\text {st }}$-order closure

- $6^{\text {th }}$-order numerical diffusion turned on 
Table A-2. Configuration of the Data Assimilation Research Testbed (DART) module

- Square root Ensemble Kalman Filter

- Cycled every 6 hours 4 times a day with various observations

- Ensemble size: 48 members

- Perturbed initial conditions from National Weather Service (NWS) Rapid Update Cycle (RUC) for first cycle

- Perturbed boundary conditions for each assimilation period, boundary conditions also from RUC

- Deterministic inflation based on spatially-varying state space (i.e. covariance inflation)

- Initial inflation standard deviation 0.6

- Initial inflation 1.0

Table A-3. Data Assimilated Every 6 Hours into the Ensemble of Simulations

\begin{tabular}{|l|l|}
\hline Assimilated observations & Validation observations \\
\hline 'RADIOSONDE_TEMPERATURE', & 'METAR_TEMPERATURE_2_METER', \\
'RADIOSONDE_U_WIND_COMPONENT', & 'METAR_U_10_METER_WIND', \\
'RADIOSONDE_V_WIND_COMPONENT', & 'METAR_V_10_METER_WIND', \\
'RADIOSONDE_SPECIFIC_HUMIDITY', & 'MARINE_SFC_U_WIND_COMPONENT', \\
'ACARS_TEMPERATURE', & 'MARINE_SFC_V_WIND_COMPONENT', \\
'ACARS_U_WIND_COMPONENT', & 'LAND_SFC_U_WIND_COMPONENT', \\
'ACARS_V_WIND_COMPONENT', & 'LAND_SFC_V_WIND_COMPONENT', \\
'ACARS_SPECIFIC_HUMIDITY', & 'DEW_POINT_2_METER',/I \\
'MARINE_SFC_TEMPERATURE', & 'LAND_SFC_TEMPERATURE', \\
'MARINE_SFC_SPECIFIC_HUMIDITY', & 'LAND_SFC_SPECIFIC_HUMIDITY', \\
'RADIOSONDE_SURFACE_ALTIMETER', & \\
'MARINE_SFC_ALTIMETER', & \\
'LAND_SFC_ALTIMETER', & \\
&
\end{tabular}

Assimilated observations are used to correct the simulated state of the atmosphere at each data assimilation time. Validation observations are used to compute evaluation statistics (e.g. root mean square error) that provide a measure of how well the model state matches the observed state of the atmosphere at a specified time. 